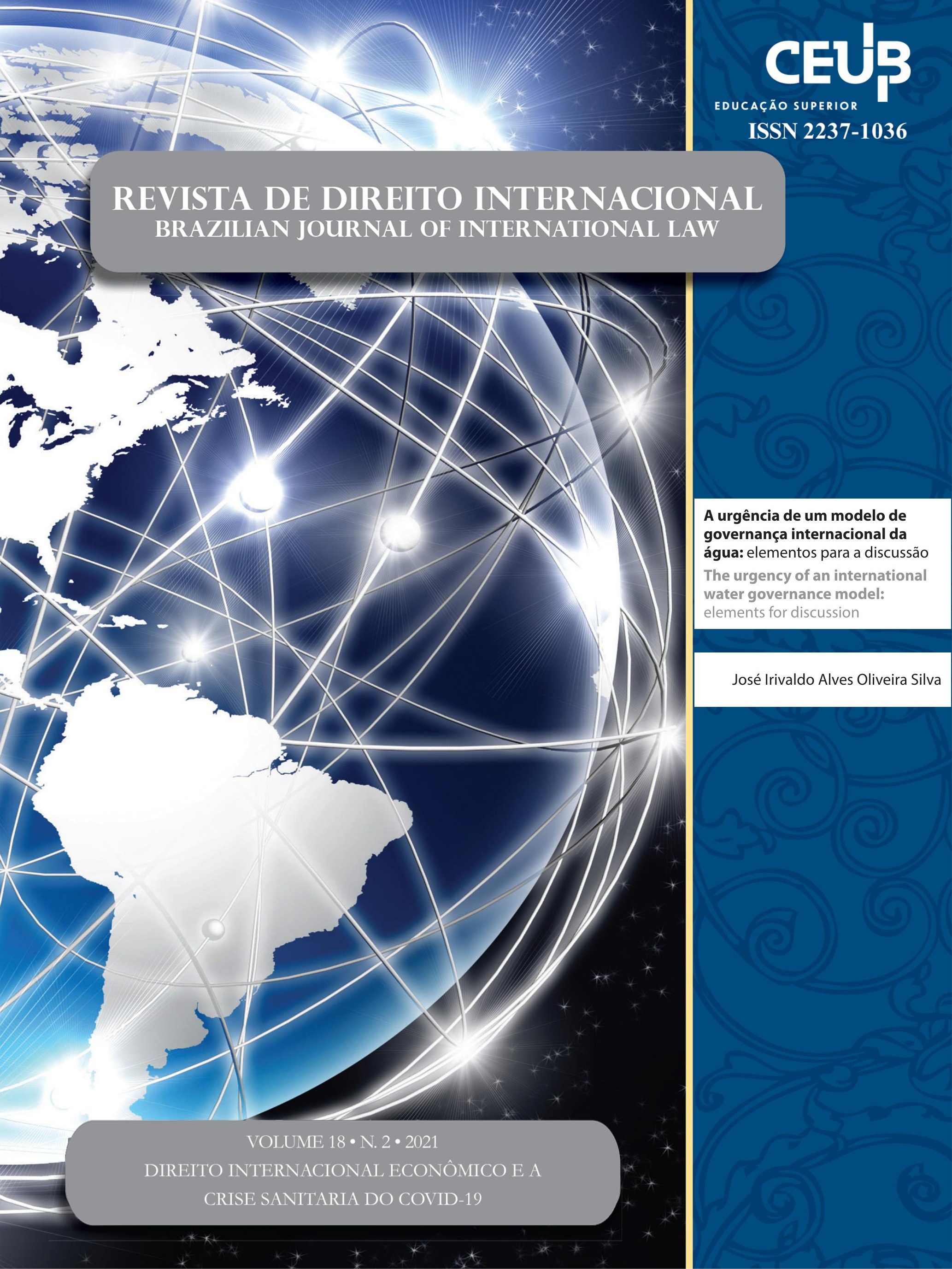




\section{Sumário}

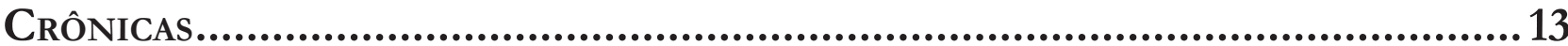

REIMAgining INTERNATIONAL RELATIONS TEACHING DURING (AND AFTER) COVID-19 ........15 Magdalena Bas

Dossiê Temático: Direito Internacional Econômico e a Crise sanitaria Do COVID-19 (INTERNATIONAL ECONOMic LaW AND THE COVID-19 SANITARY CRISIS) 19

Some QUESTIONS ABOUt INTERNATIONAL ECONOMic LAW RAISED DURING THE PANDEMIC .....21 Hervé Ascensio

International Economic LaW and the COVID-19 Sanitary Crisis: An Introduction 27 Julien Chaisse

TransparênCIA E COOPERAÇão REgUlatóRIA No COMÉRCIO INTERNACIONAL DE PRODUTOS MÉDicos PaRa a COVID-19: uMa ANÁlISE da ATUAÇão INSTITUCIONAL DA OMC E DAS NOTIFICAÇõES do Brasil EM OBSERVÂNCIA AOS ACordos TBT E SPS .35

Magali Favaretto Prieto Fernandes e Michelle Ratton Sanchez Badin

O DEVER HUMANO DE PROMOÇÃo DA SAÚDE: A AVIAÇÃo COMERCIAL INTERNACIONAL EM PERÍODOS DE CALAMIDADE SANITÁRIA E DO RETORNO À NORMALIDADE .56

Thiago de Oliveira Frizera, Luisa Cortat Simonetti Gonçalves e Adriano Sant'Ana Pedra

Police Powers Doctrine: a reliable State Defense in times of Covid-19?.... .73 Thomas Lehmann

A inexistênCia do Controle preventivo legislativo de Convencionalidade da Medida Provisória n. ${ }^{\circ} 936 / 2020$ .91

Danilo Garnica Simini, Gabriel Carvalho Moreira e Rafaela Souza Machado 
A Critical analysis of the implications of Covid-19 on piracy off the Nigerian COAST

Kalu Kingsley Anele

The COVID-19 PANDEMIC AS AN IMPELlER FOR THE AGgRAVATION OF MARINE PLASTIC POLLUTION AND ECONOMIC CRISIS: THE REVERSE EFFECT OF HEALTH PROTECTION MEASURES ON HUMAN LIVES 135

Adriana Isabelle Barbosa Lima Sá Leitão e Tarin Cristino Frota Mont’Alverne

Artigos sobre outros temas

O Direito Internacional Humanitário nos Pareceres Consultivos da Corte Internacional de Justiça: uma Conjugação de Perspectivas Utópicas e Apologéticas 156

Talis Prado Pinto Junior e Arthur Roberto Capella Giannattasio

Contesting immunities in the International Criminal Court: an analysis of the RUlings of the Pre-Trial Chambers and the Appeals Chamber in Al Bashir Case and its OUTCOMES. 171

Luisa Giannini e Roberto Vilchez Yamato

Rumo à Profissionalização da Prevenção de Controvérsias nos Acordos de CooperaÇão e Facilitação de InVEstimentos (ACFIs) do Brasil? 191

Nitish Monebhurrun e Leonardo Vieira Arruda Achtschin

THE PREVENTIVE CHARACTER OF DISASTER LAW: TAX INCENTIVES IN ENVIRONMENTAL, SOCIAL, AND GOVERNANCE (ESG) INVESTMENTS AS A RISK MITIGATION MECHANISM 212

Daniel Dela Coleta Eisaqui e Deilton Ribeiro Brasil

A URGÊNCIA DE UM MODELO DE GOVERNANÇA INTERNACIONAL DA ÁGUA: ELEMENTOS PARA A DISCUSSÃO

José Irivaldo Alves Oliveira Silva

O FIM DA HIERARQUIA SUPRALEgAL DOS TRATADOS INTERNACIONAIS: ANÁLISE DA ADI N.O 5.543/2020-DF: À luZ dA TeOria ARgumentativa de Neil Maccormick. 
Os DIREITOS HUMANOS FRENTE À NORMATIVIDADE “IMPERIAL" E A RESPONSABILIDADE DAS EMPRESAS TRANSNACIONAIS POR VIOLAÇÃO AOS DIREITOS HUMANOS NA ERA DO “IMPÉRIO” 280

Fernando Hoffmam e Jose Luis Bolzan de Morais

O RECONHECIMENTO FACIAL NAS SMART CITIES E A GARANTIA DOS DIREITOS À PRIVACIDADE E À PROTEÇÃO DE DADOS PESSOAIS.. 302

Diogo Dal Magro e Vinícius Borges Fortes

O DESENVOLVIMENTO HISTÓRICO DA PROSCRIÇÃo DO DESAPARECIMENTO FORÇADO DE PESSOAS E sua fenomenologia no Direito Penal Internacional e no Direito Internacional dos Direitos Humanos

Marcus Vinícius Xavier de Oliveira

CONSTITUCIONALISMO COOPERATIVO GLOBAL E DIREITO INTERNACIONAL PRIVADO: INSTRUMENTOS PARA UMA GOVERNANÇA DE DIREITO TRANSNACIONAL NA INTEGRAÇÃO. 362

Anderson Vichinkeski Teixeira, Roberto Correia da Silva Gomes Caldas e Luciane Klein Vieira

Proteção da inovação pela aplicaÇão do Direito da ConcorrênCia da União Europeia: ANÁLISE DA INDÚSTRIA FARMACÊUTICA.

Pablo Leurquin 


\title{
A urgência de um modelo de governança internacional da água: elementos para a discussão*
}

\author{
The urgency of an international water \\ governance model: elements for discussion
}

José Irivaldo Alves Oliveira Silva**

\section{Resumo}

O recurso mais precioso que existe no planeta é a água, o "ouro azul". Boa parte dos 2,8\% da água do planeta, que é doce, encontra-se em bacias hidrográficas internacionais. Isso significa que são compartilháveis com dois ou mais Estados soberanos. Trata-se de mais um elemento de complexidade na gestão e governança desse líquido tão vital e disputado, requerendo instrumentos internacionais cada vez mais eficazes e transparentes para preservá-lo para múltiplos usos. Portanto, as funções socioambientais da água precisam ficar preservadas. O presente ensaio pretendeu articular o desenho jurídico e administrativo dessa governança, bem como o posicionamento do conceito dela em um campo interdisciplinar e como se pode desenvolver uma governança hídrica. Utilizou-se o método dedutivo, socorrendo-se de um referencial teórico, para demonstrar o estado da arte, e também a análise de documentos do direito internacional ambiental. Verificou-se a crescente necessidade de organização de uma hidrodiplomacia preparada para os desafios frente aos conflitos originados com base no uso e acesso à água. Entretanto, necessita-se de mecanismos normativos internacionais eficazes que possam promover os múltiplos usos da água em uma perspectiva sustentável.

Palavras-chaves: Hidrodiplomacia; Água; Bacias transfronteiriças; Escassez hídrica. sidad de Alicante, Espanha. Pós-Doutor em Desenvolvimento Regional pela Universidade Estadual da Paraíba. Doutor em Ciências Sociais. Doutor em Direito e Desenvolvimento. Pesquisador Produtividade do CNPq, nível 2. Mestre em Sociologia. Especialista em Gestão das Organizações Públicas. Especialista em Direito Empresarial. Graduado em Ciências Jurídicas. Professor permanente do Programa de Pós-Graduação em Ciências Jurídicas da UFPB, Mestrado e Doutorado, bem como do Mestrado em Administração Pública e do Mestrado em Gestão e Regulação de Recursos Hídricos, ambos da UFCG. Membro da rede de pesquisa WATERLAT. Pesquisador da Rede JUST-Side (Programa Iberoamericano de Ciencia y Tecnología). Membro da Sociedade Brasileira do Design Inteligente. Membro da IUCN (International Union for Conservation of Nature) WCEL (World Comission on Environmental Law). E-mail: irivaldo.cdsa@gmail.com ou prof.irivaldo@ufcg.edu.br

\section{Abstract}

The most precious resource on the planet is water, the "blue gold". As if that were not enough, a good part of the $2.8 \%$ of the planet's water, freshwater, is found in international watersheds. This means that they are shareable with two or more sovereign states. It is yet another element of complexity in the management and governance of this vital and disputed liquid, requiring increasingly effective and transparent international instruments to preserve it for multiple uses. Therefore, the socio-environmental functions of water must be preserved. The present essay intended to articulate the legal and administrative design of this governance, as well as the positioning of its concept in an interdisciplinary field and how water governance can be developed. The deductive method was used, using a theoretical framework, to 
demonstrate the state of the art, and also the analysis of documents of international environmental law. There is a growing need to organize a hydrodiplomacy prepared for the challenges facing conflicts arising from the use and access to water. However, there is a need for effective international regulatory mechanisms that can promote the multiple uses of water in a sustainable perspective.

Keywords: Hydrodiplomacy; Water; Transboundary basins; Water scarcity.

\section{Introdução}

Nesta seção abordar-se-á uma dimensão que se considera essencial para a compreensão de uma segurança hídrica internacional, a governança, que auxiliará a gestão de uma crise hídrica global. Já se sabe que há uma crise ambiental e que, além dela, há uma crise hídrico-sanitária com causas provenientes da própria dinâmica da natureza e causas estruturais originadas, certamente, dos modelos de desenvolvimento adotados pelos governos.

A governança é importante, pois ela confere coerência no processo de gestão hídrica, uma vez que é preciso fazer funcionar bem a gestão nessa seara porque dela dependerão os múltiplos usos da água, especialmente no ciclo urbano desta, notadamente nas regiões metropolitanas. Um dos sentidos de governança está interligado ao funcionamento da gestão da água e a sua relação com o meio ambiente.

Dessa forma, constata-se que a norma é um dos pilares para o funcionamento da governança e o Brasil possui um vasto ordenamento jurídico. Em relação à gestão do ciclo urbano da água, há duas leis que estabelecem a Política Nacional de Recursos Hídricos (PNRH) e a Política Nacional de Saneamento Básico (PNSB). Além delas, há uma legislação anterior, de 1981, que criou a Política Nacional de Meio Ambiente (PNMA), dando coerência às ações necessárias para a gestão ambiental.

No campo da governança da água, há diversas escalas de aplicação: internacional, nacional, regional e local. E, nesse contexto, a unidade geoespacial hábil para a aplicação de uma governança internacional da água seria a bacia hidrográfica. À medida que se vai transitando entre essas múltiplas escalas político-administrativas, complexifica-se a governança da água, especialmente, considerando-se duas variáveis: a multiplicidade de usos da água e a multiplicidade de atores envolvidos. Dessa forma, o presente artigo traz, como problemática contemporânea a ser analisada, a possibilidade de instituição de uma governança internacional da água, diante da escassez e da pressão sobre os mananciais superficiais e subterrâneo de água ainda existentes no planeta.

Na figura 1, apresenta-se a importância de se desenhar um modelo eficaz de governança global da água. A realidade físico-geográfica de interligação dos países por meio da água se sobrepõe a uma perspectiva exclusivista e nacionalista cuja fluidez da água não segue regras fechadas hermeticamente em normas de soberania estrita. Tanto é possível estabelecer uma interligação superficial como subterrânea.

Figura 1 - águas superficiais e subterrâneas que interligam diversos países.

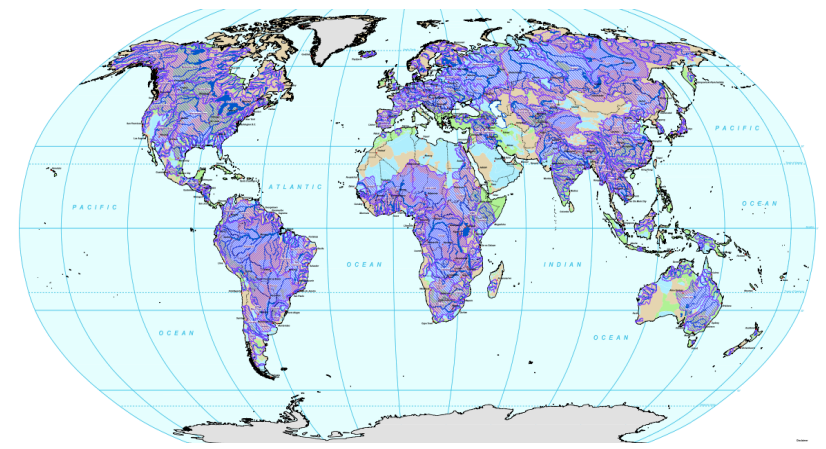

Fonte: WHYMAP - River and Groundwater Basins of the World ${ }^{1}$.

Portanto, pretende-se articular o desenho jurídico e administrativo dessa governança, bem como o posicionamento desse conceito em um campo interdisciplinar que traz elementos jurídicos, da ciência política, da ciência da administração e da sociologia. Para isso, serão abordadas as perspectivas de gestão da água e o desenvolvimento de uma governança hídrica. Enfim, são diferentes olhares para um fenômeno que é complexo na prática e que trata de diversos fatores, tais como: regras jurídicas, pessoas, posições de poder e tomada de decisão. Desse modo, organizou-se o presente artigo em dois momentos, um primeiro abordando o estado da arte da governança e um segundo de análise da normatividade do direito internacional da água.

UNESCO. River and Groundwater Basins of the world. 2012. Disponível em: https://groundwaterportal.net/resource/whymap-river-and-groundwater-basins-world Acesso em: 15 abr. 2021. 


\section{0 conceito de governança}

Nesta primeira seção, enfrenta-se o conceito de governança para, então, analisarem-se as possibilidades e obstáculos para construção de um modelo internacional. O objeto dessa governança é a água, que tem múltiplas funcionalidades, dentre elas fazer parte de um serviço público e ser um bem ambiental, fundamental para a sobrevivência da vida no planeta.

A governança é um elemento que permeia a atuação política de um governo, seja em uma esfera nacional, local ou regional. Porém, a sistemática e dinâmica da governança também estão presente nas corporações privadas, sendo uma expressão muito comum nesse campo. Desse modo, os pressupostos da governança podem absorver diferentes finalidades, dentre elas satisfazer a coletividade ou o bem-estar de investidores, por exemplo. Concorda-se com a ideia de que a governança, em geral, pressupõe o manejo de diversos recursos, sejam pessoais, sejam insumos, sejam outros essenciais para a resposta às demandas, seja na seara pública ou privada.

Russel e Scott ${ }^{2}$ abordam os fatores que compõem a governança corporativa, chamando a atenção alguns elementos como os atores públicos e privados, os recursos humanos, o ordenamento jurídico, a transparência, entre outros, porém o que é relevante mencionar que, em uma corporação privada, existe um indicador muito claro acerca do desempenho desta, o aumento de sua rentabilidade. Isso se torna mais complexo e exigente em um contexto de pulverização financista atualmente, em que os investidores observam a empresa que está tendo melhor desempenho, mobilizando capital de uma para outra. Entretanto, a preservação ambiental tem provocado pressões nesse modelo de governança mais conservador capitalista, exigindo-se parâmetros sustentáveis desses empreendimentos.

Segundo Meier e O’Toole³, é comum para o desenvolvimento de um modelo de governança a mobilização de diversos fatores que precisam interagir para que se consiga realizar alguma política pública, ou outra ação, que possa resultar em bem-estar da população. Os referidos autores destacam a atenção para o momento de escassez de recursos e de crises em que se chama à res-

\footnotetext{
2 RUSSEL, M. B.; SCOTT, C. Putting Investors First: real solutions for better corporate governance. New York: Bloomberg Press, 2003. 3 MEIER, K. J.; O’Toole L. J. Public management: organizations, governance, and performance. New York: Cambrige, 2011.
}

ponsabilidade de se colocar em vigência um modelo de governança que possa estabelecer uma performance tal que as ações públicas ocorram mesmo em um cenário de crise e escassez.

Essa exigência se conecta, diretamente, ao panorama de escassez de água, de deficiências no ciclo natural da água e do ciclo urbano da água. Porém, é importante compreender as tensões nessa compreensão acerca da governança, em especial a pública. A Global Water Patnership (GWP), organismo internacional que atua no campo do assessoramento de países para implementação de modelos de governança integrada da água, compreende essa como sendo o exercício da autoridade econômica, política e administrativa na gestão dos assuntos de um país em todos os planos ${ }^{4}$. Esse conceito é adotado também pelo Programa das Nações Unidas para o Desenvolvimento ${ }^{5}$. Entretanto, acredita-se que o conceito mais adequado de governança que irá auxiliar a construção de um modelo internacional de gestão dos recursos hídricos vai mais além.

Debates e definições de governança surgiram em diferentes escalas espaciais e em diferentes tipos de instituições e campos acadêmicos. O termo "governança" tem sido utilizado em vários países da Europa Ocidental, Estados Unidos, Canadá, Austrália e Nova Zelândia e, posteriormente, tornou-se um tema dominante nas organizações internacionais, particularmente no Banco Mundial e nas Nações Unidas. Na literatura ocidental, preocupa-se, principalmente, com a ideia de uma mudança da percepção realista do antigo governo e do sistema da Vestfália, segundo o qual o mundo está organizado em estados-nação soberanos e territorialmente exclusivos, cada um com um monopólio interno da violência legítima, para uma nova governança mais comunitária. O primeiro é caracterizado por ter uma administração que é considerada o ator dominante e chave na arena política. Internamente, existe uma clara hierarquia de autoridade, e o governo é visto como um processo hierárquico de cima para baixo, com o estado nacional ocupando o centro. No entanto, com a mudança de governo para governança, a administração governamental agora é apenas um ator dentre muitos outros na arena política. Essa arena se tornou visivelmente mais movi-

\footnotetext{
4 GLOBAL WATER PARTNERSHIP. Gobernabilidad Efectiva del Agua. Montevideo: GWP, 2006.

UNITED NATIONS DEVELOPMENT PROGRAMME. Governance for sustainable buman development. a UNDP policy document.
} New York: UNDP 1997. 
mentada, há mais atores envolvidos, as fronteiras entre a esfera pública e a privada são menos precisas e diz-se que o comando do governo sobre o processo político foi transformado ${ }^{6}$.

Um modelo linear de governança, ao que parece, não se adequaria mais aos diversos modelos de organizações existentes, notadamente no campo da gestão da água. A complexidade dos cenários apresenta a necessidade de um modelo que contemple os diversos atores presentes e que estão interagindo. Um tipo centralizado de exercício de poder dos Estados foi limitado pela ação de outros atores que estão presentes no processo político de implementação de políticas públicas.

Isso é confirmado e reforçado por Raadschelders, Vigoda-Gadot e $\mathrm{Kisner}^{7}$ em estudo amplo sobre a administração pública pelo mundo, em que os poderes centralizados têm perdido espaço, principalmente, quando se pensa na eficácia de políticas públicas como água e saneamento, mesmo considerando-se que a busca no campo das relações entre nações tem sofrido o impacto de novos movimentos nacionalistas. Mas essa é outra história. No campo interno da administração, observa-se uma performance de estruturas organizacionais que sabem articular os diversos fatores resultando no atendimento das demandas.

É inevitável ligar governança a exercício do poder, mas insiste-se em pensar que aquela vai mais além, passando por estratégias, resultados, modelos, a forma como se exerce autoridade e se delega poder. Mark e Hooghe referem-se à governança contemporânea como multiformas de exercer o poder.

\footnotetext{
The diffusion of authority in new political forms has led to a profusion of new terms: multi-level governance, multi-tiered governance, polycentric governance, multi-perspectival governance, functional, overlapping, competing jurisdictions (FOCJ), fragmegration (or spheres of authority), and consortio and condominio, to name but a few. ${ }^{8}$
}

\footnotetext{
${ }^{6}$ KENNETH, P. Governance, globalization and public policy. Great Britain: Edward Elgar Publishing Limited, 2008.

RAADSCHELDERS, J. C. N.; VIGODA-GADOT, E.; KISNER, M. Global dimensions of public administration and governance. United States of America: John Wiley \& Sons, Inc., 2015.

8 A difusão de autoridade em novas formas políticas levou a uma profusão de novos termos: governança em vários níveis, governança em camadas, governança policêntrica, governança em múltiplas perspectivas, jurisdições funcionais, sobrepostas e concorrentes (FOCJ), fragmentação (ou esferas de autoridade) e consórcio e condomínio, para citar apenas alguns. MARK, G.; HOOGHE, L. Contrasting visions of multi-level governance. In: BACHE, I.; FLINDERS, M. Multi-level Governance. Oxford: [s.n.], 2004. p. 15. (Tradução livre).
}

Pereira ${ }^{9}$ estabelece que, a despeito da origem da expressão governança, que advém do setor privado, ela é aplicável ao setor público e sua função é preponderantemente organizacional. Assim ele pontua: "seria uma forma de transformar a complexidade desestruturada em uma complexidade estruturada, ainda que não se pudessem controlar os 'n' efeitos da simplificação e estruturação pretendidas". A governança é sistema que busca dar coesão às decisões, desde que cumpra os princípios e objetivos para os quais ela foi desenhada. Concorda-se com o apontamento de Tovar et al. ${ }^{10}$ quando constatam que há múltiplos usos do vocábulo governança, principalmente confundindo com governabilidade, governo e governar. $\mathrm{Na}$ visão de Tovar et al. ${ }^{11}$, a governança tem as seguintes características:

1. es el proceso por el cual se seleccionan, son supervisados
los gobiernos, 2. es la capacidad del gobierno de formular
y de aplicar politicas sanas con eficacia, y 3. es el respeto de
ciudadanos y el Estado para las instituciones que gobiernan
las interacciones económicas y sociales entre ellas. ${ }^{12}$

Dessa forma, pode-se asseverar que um bom conceito de governança traz elementos de autoridade, de governo e jurídicos que orientam as regras do "jogo", bem como elementos da administração pública e gestão pública que poderão auxiliar no desenvolvimento, ou implementação de políticas públicas. Parece que o governo em si não importa tanto em comparação à ação de governar. Essa ação de governar, como se procede e como se chega ao desiderato proposto em uma determinada política, são elementos necessários para uma governança significativa, que cause impacto na sociedade ${ }^{13}$. Portanto, um modelo de governança exclusivamente jurídica ou exclusivamente gerencial não representa um conceito holístico que possa abarcar as relações sociais complexas contemporâneas.

\footnotetext{
9 PEREIRA, R. R. Governança no Setor Público: origem, teorias, modalidades e aplicações. Revista do TCU, n. 122, 2011. p. 121.

10 TOVAR, L. A. R.; FLORES, M. T. e VILCHIS, F. L. La gobernanza. Conceptos, tipos, e indicadores internacionales: Los retos para México. México: Alta Impresión S.A, 2015.

11 TOVAR, L. A. R.; FLORES, M. T. e VILCHIS, F. L. La gobernanza. Conceptos, tipos, e indicadores internacionales: Los retos para México. México: Alta Impresión S.A, 2015. p. 577.

12 1. é o processo pelo qual os governos são selecionados, supervisionados; 2. é a capacidade do governo de formular e implementar políticas saudáveis de forma eficaz; e 3. é o respeito dos cidadãos e do Estado pelas instituições que governar as interações econômicas e sociais entre eles.

13 CASTELLANOS, C. E. Q. Gobernanza y teoría de las organiza-
} ciones. Perfiles Latinoamericanos, v. 25, n. 50, p. 39-57, 2017. 
Kooiman ${ }^{14}$, reconhecido como grande referência teórica no campo dos estudos de governança, endossa a compreensão de que se está inserido em uma sociedade diversa, dinâmica e complexa e que, portanto, a despeito de variados formatos de governança, uma que seja eficaz, ou que se pretenda ser, deveria considerar essas três dimensões. Assim, o arremate nessa seção considera que o conceito de governança está atrelado ao cumprimento de objetivos e à forma como se procede para atingi-los.

Especificamente um modelo de governança pública, que interessa aqui, deve ser elaborado com a intenção de implementar políticas públicas, que são ações de governo baseadas em uma racionalidade, em um caminho que inicia na agenda pública, avança para a formulação de uma proposta com base nas demandas dessa agenda, resulta na implementação e deve ser avaliada. O direito é fundamental nesse processo, uma vez que ele estabelece as regras, podendo instituir, inclusive, a própria política discutida e planejada no âmbito da discricionariedade do administrador, que esteja no governo. Os modelos de governança das políticas de água e saneamento, por exemplo, são previstos em lei. O Direito Internacional Público (DIP) pode ser a expressão maior para a formação e consolidação de um modelo global de governança da água.

\subsection{Fundamentos e diretrizes para uma governança da água}

Na presente subseção, abordar-se-á a governança da água, uma vez que é elemento essencial para se pensar em fundamentos ecológicos para um conceito adequado de gestão da água, norteando o planejamento em mananciais transfronteiriços. O pressuposto inicial para isso é o reconhecimento de uma crise em face do ciclo da água que tem consequências no ciclo urbano desta, caracterizada por uma superexploração da água superficial e subterrânea especialmente pelas atividades agrárias e industriais, e o lançamento dessas águas utilizadas sem o devido tratamento no meio ambiente ${ }^{15}$. Portanto, há duas questões crucias para a governança internacional: a quantidade da água com qualidade disponível para

\footnotetext{
14 KOIMMAN, J. Modern Governance: new goverment, society interactions. Great Britain: Sage, 1993.

15 SILVA, J. I. A. O. Segurança hidrica ecológica: fundamentos para um conceito jurídico. 2020. Tese (Doutorado em Ciências Jurídicas) Universidade Federal da Paraíba, João Pessoa, 2020.
}

as atividades essenciais à vida no planeta e o tratamento destas quando de sua utilização e lançamento de volta para o meio ambiente ou para um sistema de reuso.

Entretanto, é fundamental pensar que a governança não se confunde com governo, nem governabilidade, tendo uma relação intrínseca essencial. $\mathrm{O}$ conceito utilizado pela $\mathrm{GWP}^{16}$ fala em governabilidade da água, porém entende-se que a expressão mais apropriada para o contexto contemporâneo seria governança da água. Moraes e Licea ${ }^{17}$, com base na realidade dos países hispânicos, que acabou por se irradiar a outros países, como o Brasil, afirmam que a governabilidade foi aplicada para o desenvolvimento econômico e o conceito de governança, seja ela hídrica ou não, tendo como pilares a democracia, a transparência e o diálogo com os atores sociais. É evidente que, para que haja governabilidade de uma forma mais geral, é fundamental que as políticas públicas tenham boa governança. Entretanto, um aspecto fundante que precisa ser considerado é a planificação de projetos hídricos, muito presentes com a finalidade de abastecimento e fornecimento de vários serviços às regiões metropolitanas, mas que precisam estender esse planejamento para o campo internacional em regiões tranfronteiriças. Em termos de país, precisa-se ter um planejamento do compartilhamento de água entre os Estados soberanos. $\mathrm{Na}$ linha que Viñuales defende, é preciso uma ampla sintonia entre elementos internos e internacionais de governança da água, que reforça a perspectiva holística defendida neste artigo ${ }^{18}$.

Em 2006, o World Water Development Report $2^{19}$ apontou a essencialidade da mudança da governança no processo de distribuição equitativa da água. Aponta ainda mudanças no conceito de governança, que foi aprimorado. Entretanto, verificou-se maior estresse hídrico, ou seja, diminuição da disponibilidade, em países com problemas de governabilidade, marcados pela limitação de direitos individuais e liberdade; aponta a importância do trabalho colaborativo entre os atores interessados como essencial para o êxito de uma política pública de água; a maioria dos países não conseguem atingir o estágio de

\footnotetext{
16 GLOBAL WATER PARTNERSHIP. Gobernabilidad Efectiva del Agua. Montevideo: GWP, 2006.

17 MORAES, D. S.; LICEA, D. M. El péndulo de la gobernabilidad y la governanza del agua en México. Tecnología y Ciencias del Agua, v. 4, n. 3, p. 149-163, jul./ago. 2013.

18 VINUALES, J. E. The protocol on water and health as a strategy for global water governance integration. ICLQ, v. 68, p 175-192, jan. 2019.

19 UNESCO. World Water Development Report. Oxford: Unesco, 2006.
} 
implementação da política; reformas nacionais na gestão da água, quando aplicáveis; aponta, também, a corrupção como um obstáculo importante a ser superado; considera a governança como intrinsecamente ligada aos arranjos políticos e de poder; e, principalmente, aponta que cada sociedade deve encontrar seu próprio caminho ou modelo. Destaque-se o seguinte trecho desse relatório:

\begin{abstract}
Important to develop institutions and governance systems that can respond effectively to situations characterized by variability, risk, uncertainties and change. Conventional water planning remains rigid and the challenge remains to develop adaptive governance frameworks and institutions. More attention needs to be given to resilient institutions and approaches that can govern or guide the complex, surprise-laden process of water governance central to long-term management at regional, basin, aquifer and local levels. ${ }^{20}$
\end{abstract}

Ao que parece, a palavra de ordem seria "adaptação" da governança no contexto de mudanças rápidas e de limitação de recursos. O referido relatório ainda insere os mecanismos institucionais e jurídicos como sendo responsáveis diretos para colocar em prática uma gestão integrada da água, principalmente no aspecto da governança, sendo estratégicos. $\mathrm{O}$ atual relatório traz um diagnóstico mais aprofundado das condições de acesso à água e saneamento, além de adicionar temas novos como os relacionados aos refugiados da escassez, pessoas que saem de suas terras por causa da falta de água somada a outras condições precárias ${ }^{21}$. O referido documento também deixa como referencial as seguintes característica de uma boa governança a partir dos dados coletados:

1) good governance relates to systems that have qualities of accountability, transparency, legitimacy, public participation, justice and efficiency and therefore overlaps with the principles of the $H R B A$.;

2) good water governance involves pro-active measures and mechanisms, ensuring guidance towards effective implementation along with sanctions against poor performance, illegal acts and abuses of power;

3) eeks to move away from hierarchical power structures;

4) the positive impact of good governance (and the negative impact of corruption) has been proved to affect the efficiency of water utilities;

\footnotetext{
20 É importante desenvolver instituições e sistemas de governança que possam responder, efetivamente, a situações caracterizadas por variabilidade, risco, incertezas e mudanças. O planejamento convencional da água permanece rígido e o desafio continua a desenvolver estruturas e instituições de governança adaptáveis. É necessário dar mais atenção às instituições e abordagens resilientes que possam governar ou orientar o processo complexo e cheio de surpresas da governança da água, central para a gestão de longo prazo nos níveis regional, de bacia, aquífero e local. UNESCO. World Water Development Report. Oxford: Unesco, 2006. p. 9. (Tradução livre). 21 UNESCO. World Water Development Report. México: Unesco, 2019.
}

5) empower the most disadvantaged groups - is essential for successful implementation of water policies ${ }^{22}$;

Com base nesses pressupostos, refletem-se as modalidades e a conexão com a governança pública da água. Para isso o marco teórico aqui adotado foi Kooiman ${ }^{23}$ e Dunrise ${ }^{24}$, uma vez que a preocupação central é como compatibilizar os modos de governança com os momentos pós-modernos que se caracterizam pela fugacidade. Esses autores dividem a governança em quatro modalidades.

\subsubsection{Governança por regulação}

Essa parece ser a mais usual, uma vez que o objeto das administrações públicas é justamente elaborar propostas de políticas públicas e implementá-las, o que é a grande dificuldade conforme o relatório das nações unidas aqui citado. Os protagonistas desse processo são os políticos que comandam o processo legislativo, buscando criar mais normas, mais políticas, pois, assim, eles conseguirão êxito em sua carreira pública como mandatários. Essa modalidade fica tanto mais fácil quando se tem as rédeas do processo.Em modelos presidencialistas de coalizão, o governo central terá condições de promover mudanças nas políticas e criar novas políticas públicas conforme sua base no parlamento ou mesmo por ações monocráticas como por meio das medidas provisórias.

Dunrise $^{25}$ aponta que é deveras caro esse processo e que seu tempo de duração pode ser considerável, além

22 1) A boa governança refere-se a sistemas que possuem qualidades de responsabilidade, transparência, legitimidade, participação do público, justiça e eficiência e, portanto, se sobrepõem aos princípios do HRBA (human rights-based approach - abordagem baseada nos direitos humanos. 2) A boa governança da água envolve medidas e mecanismos proativos, garantindo orientação para uma implementação eficaz, juntamente com sanções contra o mau desempenho, atos ilegais e abusos de poder. 3) Procura afastar-se das estruturas hierárquicas de poder. 4) Provou-se que o impacto positivo da boa governança (e o impacto negativo da corrupção) afeta a eficiência dos serviços públicos de água. 5) Capacitar os grupos mais desfavorecidos - é essencial para a implementação bem-sucedida das políticas de água. UNESCO. World Water Development Report. México: Unesco, 2019. p. 4, 82, 90, 151, 158. (Tradução livre).

23 KOIMMAN, J. Modern Governance: new goverment, society interactions. Great Britain: Sage, 1993.

${ }^{24}$ DUNRISE, A. Manipulating Social Tensions: collibration as an alternative mode of government intervention. 1993. Disponível em: https://www.econstor.eu/bitstream/10419/43732/1/152565922.pdf Acesso em: 13 abr. 2021.

25 DUNRISE, A. Manipulating Social Tensions: collibration as an alternative mode of government intervention. 1993. Disponível em: 
do que está suscetível a obstáculos e distúrbios pelo caminho. Segundo ele, remédios lineares não se coadunam com casos não lineares. Parece que esse é o caso dos problemas ambientais. Entretanto, considera-se perigoso defender uma desregulação da proteção ambiental, ou mesmo especificamente da água, evitando-se que se desconstrua um sistema de normas que protege alguns bens inestimáveis para a humanidade. Porém, o autor preconiza a necessidade de não regular, por exemplo, alguns setores, principalmente o mercado, sendo imprescindível incentivar a autorregulação. Chama atenção para a característica sistêmica que menciona acerca das organizações que se interligam e precisam estar em bom funcionamento para o todo funcionar corretamente, sem dispensar um modelo hierárquico de disposição dos atores. O uso das normas nesse modelo é característica essencial. Pavão et al. ${ }^{26}$, citando o caso brasileiro, teme pela fragmentação normativa e não abordagem de uma agenda pública sobre água que seja pautada por prioridades. Essa mesma fragilidade pode ser encontrada em outros países e no campo da horizontalidade normativa internacional.

\subsubsection{Governança sem governo}

A princípio esse modelo traz desconfiança acerca do seu significado. Pensa-se que ele está descartando a institucionalidade. $\mathrm{Na}$ verdade, esse modelo vai de encontro ao pensamento que estabelece uma dependência muito forte do Estado, ou seja, a ligação umbilical face à sua estrutura. É como se toda organização da sociedade, para ser bem-sucedida nos seus intentos, precisasse necessariamente do Estado $^{27}$. Seria como se os caminhos fossem naturalmente encontrados. O equilíbrio seria o objetivo.

Claro que isso destoa, por exemplo, da separação dos poderes, cujo princípio está inscrito nas constituições modernas, pois é um mecanismo, não natural, para fazer com que um poder não se sobreponha aos outros:

https://www.econstor.eu/bitstream/10419/43732/1/152565922. pdf Acesso em: 13 abr. 2021.

26 PAVÃO, B. B. M.; SALINAS, N. S. C.; VIGAR, T. do N. Regulação das águas: uma análise empírica da produção normativa dos órgãos reguladores federais. Revista Brasileira de Políticas Públicas, Brasília, v. 11, n. 1. p. 319-341, 2021.

27 DUNRISE, A. Manipulating Social Tensions: collibration as an alternative mode of government intervention. 1993. Disponível em: https://www.econstor.eu/bitstream/10419/43732/1/152565922. pdf Acesso em: 13 abr. 2021. isto pode acontecer, mas o sistema cria possibilidades de rechaçar, prevenindo ou atuando quando ocorra uma violação. Neste artigo, esboça-se uma tentativa de, partindo de princípios, poder-se pensar em modelos de governança pública internacional para a água e saneamento, uma vez que este seria o caminho mais apropriado para o enfrentamento da maior crise de escassez de água no século $\mathrm{XXI}^{28}$.

\subsubsection{Collibration}

Essa expressão marca a pesquisa de Dunrise, uma vez que a inquietação que o atingia dava conta que não haveria um modelo perfeito, fechado que pudesse ser uma receita genérica para todos os casos, ou a maioria deles. A collibration carateriza-se por uma espécie de coordenação ${ }^{29}$. Porém, para que isso ocorra, um requisito é basilar: informações. Portanto, é inevitável que se relacione essa questão ao Princípio da Transparência.

Os atores que participam do processo de governança precisam ter informações acessíveis. A disponibilização de informações expõe os atores de forma tal que, possivelmente, demonstra as razões favoráveis e contrárias, aplicáveis ao planejamento urbano e às questões ambientais, sendo fundamental a criação de arenas, tratando-se de um caminho salutar para a depuração de algo que não venha trazer vantagens ao interesse público. Nesse caso é preciso lembrar da presença da corrupção como um fenômeno global quando se trata de recursos naturais e a transparência é um mecanismo que auxilia na prevenção e no combate ${ }^{30}$. Lembrando que o vocábulo librate vem de calibrar. Dunrise define, assim, collibration:

as an intervention by government to use the social energy created by the tension between two or more social groupings habitually locked in opposition to one another to achieve a policy objective by altering the conditions of engagement without destroying the tension - unless deliberately. ${ }^{31}$

28 Srinivasan, V. et al. The nature and causes of the global water crisis: Syndromes from a meta-analysis of coupled human-water studies. Water Resources Research, v. 48, 2012.

29 DUNRISE, A. Manipulating Social Tensions: collibration as an alternative mode of government intervention. 1993. Disponível em: https://www.econstor.eu/bitstream/10419/43732/1/152565922. pdf Acesso em: 13 abr. 2021.

30 VINUALES, J. E.; LEES, E. Comparative environmental law. United Kingdom: Oxford University Press, 2019.

31 Como uma intervenção do governo para usar a energia social criada pela tensão entre dois ou mais grupos sociais habitualmente travados em oposição um ao outro para alcançar um objetivo político, alterando as condições do engajamento sem destruir a tensão 
Basicamente, o desenho desse modelo consiste em grupos de pressão que atuam nesse processo de governança e que a existência de informação, seja oficial, seja por meio da mídia, é essencial nessa "batalha", como Dunrise classifica, para que se tenha um resultado positivo mais à frente. Essas arenas são produzidas e reproduzidas na sociedade e se concretizam como o mercado e seus agentes, o Estado, e outros atores, daí a necessidade de mediação. A pulverização da quantidade de atores dificulta esse modelo de coordenação e direção que pressupõe uma calibragem, sendo o menos difícil de regular a governança composta pela mediação de organismos ou instituições. O trecho a seguir pode auxiliar a compreensão da complexidade da governança da água, considerando os atores que estão envolvidos e o objeto de regulação.

\section{The decrease in effective power of the government actor, on the other hand, means that the classic modes of intervention, by legislation and policing of imposed standards, do not work where the government lacks the expertise and the information to know what to prescribe, the means to detect when things are going wrong, or the "clout" to change things when they do. Other less obtrusive, less abrasive, less knowledge-hungry interventions will do better. ${ }^{32}$}

O setor de água é complexo e necessita de modo premente de conhecimento específico, similar ao descrito pelo autor. Esse modelo foi também adotado para o setor de águas, que é eminentemente público, e que tem um perfil diferenciado. Além disso, o Brasil adota um processo de formalização de arenas por meio de suas legislações gerais que regulam setores como água e saneamento.

\subsubsection{Controlabilidade}

A respeito desse último tipo de governança, o pressuposto é pensar que a sociedade é permeada por relações sociais que têm suas dinâmicas, muitas vezes diversas, e passam, via de regra, por turbulências, principalmente porque há uma pluralidade de atores, muitos com certo grau de autonomia e que visam maximizar seus próprios interesses. Isso aponta para a necessidade de um modelo flexível, adaptativo, mas que tenha como "coluna vertebral" a coordenação e direção em busca do equilíbrio. A presença ou não do governo precisa ser contextualizada, considerando-se seu caráter público e, portanto, a busca por satisfazer o interesse coletivo.

A Teoria da Governança aponta para a necessidade de se enveredar na busca da estabilização de conflitos, eles são inevitáveis. Por isso a controlabilidade poderia ser adotada como uma diretriz de uma governança mais atual. Entretanto, o difusionismo da própria noção de governança aponta para o contexto da realidade que será o definidor de como se deve agir, com o complicador de que os elementos de governança acabam sendo utilizados e se adequando a diversas situações, como é o caso da água ${ }^{33}$. Dessa forma, pode-se aplicar o que foi discutido neste artigo e apresentado como princípios e fundamentos para uma governança que possa ser a mais adequada possível entre os diversos atores que são interessados na gestão de águas, dentre eles os usuários em geral, pessoas físicas e jurídicas, o setor público, o setor privado, incluindo o setor agrícola, que tem grande participação no consumo do estoque de água do planeta.

Portanto, pode-se apontar que a gestão da água seria a governança dos interesses dos atores implicados em todo o processo de utilização da água, desde a captação a partir do ciclo da água, construção de infraestruturas que cuidarão para que o ciclo urbano da água funcione, bem como haja, também, abastecimento difuso para comunidades mais distantes dos centros urbanos. Percebe-se que há a necessidade inarredável de uma coordenação, de uma direção, para que as diversas arenas que estão postas possam estar em um contexto de menor conflito e, até, de potencial equilíbrio.

33 GOMIDE, J. E.; SILVA, A. C. O surgimento da expressão "governance", governança e governarça ambiental. Revista de Ciências Gerenciais, v. 13, n. 18, 2009. Katsamunska, P. The concept of governance and public governance theories. Economic Alternatives, n. 2, 2016.

(Tradução livre). 


\subsection{A governança da água na ótica de Ostrom}

Outra diretriz para uma governança eficaz é um conjunto normativo que dê segurança jurídica às tomadas de decisão dos órgãos envolvidos, absorvendo os princípios que dão um caráter sistêmico a todas as ações concernentes à gestão e governança do ciclo da água, amparando o mínimo necessário ao consumo humano e manutenção dos ecossistemas. Entretanto, a governança da água é extremamente peculiar, uma vez que se está falando de um recurso comum limitado, que depende de um ciclo natural para sua produção. Além disso, a distribuição precisa ser justa, sendo seu fundamental a vida no planeta. $\mathrm{O}$ uso irracional impacta os estoques existentes produzindo uma situação de escassez estrutural $^{34}$.

A governança da água é complexa justamente por conta desses dois elementos: trata-se de um recurso comum e que depende da ação de diversos atores. $\mathrm{Na}$ verdade, tem-se o que Ostrom et al..$^{35}$ relataram em uma de suas publicações acerca do problema da Common-pool (recurso comum), ou seja, do processo de excesso de exploração de um recurso comum que pode servir, por exemplo, para algum projeto de desenvolvimento, como a água, que seria um exemplo clássico dessa questão. Ostrom $^{36}$ menciona três pontos que são essenciais para uma análise institucional contemporânea da governança de recursos comuns como a água e que pode ser o $b a$ ckground teórico nesse campo, mas que não satisfazem, necessariamente, uma análise completa do problema:

a) Os usuários de recursos são maximizadores livres de normas de ganhos imediatos, que não cooperarão para superar os dilemas comuns que enfrentam;

b) Projetar regras para mudar os incentivos dos participantes é uma tarefa analítica relativamente simples; e

c) A própria organização requer direção central.

Esse seria o panorama de uma organização, em que diversos atores dependem do mesmo recurso. Entretanto, para Elinor Ostrom ${ }^{37}$, todas as formas de tomada de

\footnotetext{
34 PACHECO-VEGA, R. Ostrom y la gobernanza del agua en México. Revista Mexicana de Sociología, v. 76, n. Esp., p. 137-166, set. 2014. 35 OSTROM, E.; GARDNER, R.; WALKER, J. Rules, Games and Common Pool Resources. United States of America: The University Michigan Press, 1994.

36 OSTROM, E. Coping with tragedies of the Commons. Annu. Rev. Polit. Sci., n. 2, 1999. p. 493.

37 OSTROM, E. Coping with tragedies of the Commons. Annu.
}

decisão têm limites. Os limites de uma série de sistemas de governança de recursos completamente independentes devem ser discutidos, bem como a importância de criar sistemas de governança policêntricos com considerável sobreposição para combinar os pontos fortes dos processos de pesquisa e design paralelos com os pontos fortes de sistemas maiores na resolução de conflitos, aquisição de conhecimento científico, monitorando o desempenho de sistemas locais e a regulamentação de recursos comuns que são mais globais em seu escopo.

Os sistemas de governança policêntricos resultantes não são geridos por um único centro. Eles também são sistemas adaptativos complexos, e exigem que os analistas de políticas alterem suas visões fundamentais da organização, a fim de lidar, com mais eficácia, as tragédias dos bens comuns e muitos dos outros problemas que as sociedades modernas enfrentam. Esse parece ser um modelo teórico com as características mais próximas de uma governança efetiva da água.

Os cursos de água provenientes de fontes diversas, superficiais e subterrâneas se enquadram no conceito de recursos comuns de Ostrom, uma vez que tais modalidade de recursos têm grandes dificuldades em excluir usuários, bem como há o problema dos free riders, além do que alguns indivíduos podem superexplorar o recurso trazendo prejuízos para outros usuários, uma vez que se está falando de um sistema comum ${ }^{38}$. Porém, as situações são muito diversas, os estudos de Ostrom identificaram elementos comuns a todas as situações estudas $^{39}$ : 1) participantes; 2) posições; 3) ações; 4) resultados; 5) transformação em funções que liguem ações a resultados; 6) informações; e 7) recompensas (incluindo tanto retornos positivos como sanções negativas quando relevantes).

Nesse contexto, é preciso compreender as interações humanas no âmbito institucional, sendo relevante perceber a sua diversidade diante da complexidade de situações vivenciadas no contexto da humanidade ${ }^{40}$. As ações estão interligadas, e podem estar sob os cuidados de uma organização maior que tem um papel na socie-

Rev. Polit. Sci., n. 2, 1999. p. 493-535.

38 OSTROM, E.; GARDNER, R.; WALKER, J. Rules, Games and Common Pool Resources. United States of America: The University Michigan Press, 1994.

39 OSTROM, E. Coping with tragedies of the Commons. Annu. Rev. Polit. Sci., n. 2, 1999. p. 493.

40 OSTROM, E. Understanding Institutional Diversity. Printeton: Princeton University, 2005. 
dade. Essa é uma questão enfrentada no campo da governança ambiental e, por conseguinte, na governança da água. São muitos riscos e muitas engrenagens, uma dependente da outra. Portanto, na visão de Ostrom o comportamento humano é influenciado pela ação dessas instituições.

No caso específico da água, bem como do saneamento, há diversos atores envolvidos, participantes interessados, que se interrelacionam por meio de instituições que compõem o sistema de regulação. A governança da água se sobrepõe aos demais sistemas relacionados, como o saneamento, uma vez que se entende que este pode ser derivado e influenciado pela primeira. O ciclo natural da água com o ciclo urbano da água deve ser a preocupação central dessa governança institucionalizada com a presença de diversos "jogadores".

Assim, sob essas bases iniciais, Ostrom discute a eficiência ou não de modelos policêntricos, ou seja, diversas instituições interrelacionadas mas sem um centro de controle específico, mas diversos controles por setor. Esses setores têm certa autonomia, o que, segundo pesquisas, não traz nenhum resultado caótico ${ }^{41}$. A governança da água, mesmo em modelos mais centralizados, ainda assim é composto por diversas escalas onde decisões são tomadas. Portanto, é praticamente inevitável uma governança policêntrica da água. Esta é caracterizada por um grau maior ou menor de descentralização. Isso deve ocorrer, também, no plano internacional. Ostrom aponta, em suas pesquisas, que a água se adequa ao conceito de common pool, ou recursos comuns, uma vez que é extraído por diversos atores que perpassam por uma diversidade institucional extraordinária ${ }^{42}$.

$\mathrm{Na}$ natureza a água está disposta de forma livre, acessível para os nativos e de difícil fiscalização muitas vezes pelo Poder Público quando se tratam de usuários produtores agrícolas, de pequena, média ou grande porte, de mineradores que utilizam a água no processo de extração e beneficiamento de minério, entre outros. Porém, ao Estado cabe, na maior parte das situações, esquadrinhar os múltiplos usos da água, seja para o setor produtivo, para geração de energia ou uso doméstico.

\footnotetext{
${ }^{41}$ OSTROM, E. Beyond markets and states: polyjcentric governance of complex economic systems. American Economic Review, n. 100, p. 641-642, 2010.

42 OSTROM, E. Coping with tragedies of the Commons. Annu. Rev. Polit. Sci., n. 2, 1999. p. 493-535.
}

Assim Ostrom ilustra essa questão do uso de recursos comuns e sua regulação:



A tarefa é complexa, pensando em um nível micro, imagine-se para o compartilhamento entre países, sendo preciso ter um nível de sofisticação extraordinário que, entretanto, possa ter uma base nessa Teoria Institucionalista de Ostrom, considerando-se um recurso comum a que todos têm acesso de forma controlada, descentralizada, mediado por órgãos públicos, por agências públicas, empresas privadas ou organismos de usuários. Portanto, a grande questão para a governança pública da água é como distribuí-la, de forma equitativa, entre os diversos usuários, sem que se esqueçam, nesse conjunto, nessa rede, os ecossistemas que precisam de água de boa qualidade, com necessária revisão do conceito e da noção de governança internacional da água.

\section{A governança internacional da água}

Contando-se apenas com as águas superficiais, é possível chegar a uma taxa de $45 \%$ de ocupação terrestre pelas bacias transfronteiriças ou compartilhadas entre países ${ }^{44}$. Mais da metade da população mundial

\footnotetext{
43 Tang também descobriu que muitos sistemas de irrigação usam diferentes conjuntos de regras, dependendo da disponibilidade de água. Durante a estação mais abundante, por exemplo, os irrigadores podem ser autorizados a levar água sempre que necessário. Durante uma temporada em que a disponibilidade de água é moderada, os agricultores podem usar um sistema de rotação no qual todo agricultor está autorizado a tomar água por um período fixo de tempo durante a semana, com base na quantidade de terra a ser irrigada. Durante a escassez, o sistema de irrigação pode empregar um distribuidor especial de água que esteja autorizado a alocar água para os agricultores que cultivam culturas autorizadas pelo sistema de irrigação e que mais necessitam. OSTROM, E. Coping with tragedies of the Commons. Annu. Rev. Polit. Sci., n. 2, 1999. (Tradução livre).

44 WALSCHOT, M. Hidro-diplomacia y soberanía nacional en el acuífero guaraní: ¿fracaso de un intento de gestión transfronteriza por intereses geopolíticos divergentes? Agua y Território, n. 15, p. 2134,2019
} 
depende diariamente da água compartilhada entre dois ou mais países, sejam águas superficiais, provenientes de rios e lagos, bem como de águas subterrâneas transfronteiriçcas ${ }^{45}$. Desse total, as águas subterrâneas perfazem a maior parte do volume total de água transfronteiriças, sendo mais de 600 aquíferos nessas zonas de fronteira entre países ${ }^{46}$.

Dessa forma, é importante compreender o lugar da água em uma geopolítica dos recursos naturais. Nesse campo a água ocupa um lugar de destaque, pois certamente é hoje uma espécie de "ouro azul", cuja transformação em uma commodity está em processamento, embora reúna características muito especiais que destoam da mercantilização global desse recurso. $O$ primeiro mercado de futuros de água foi criado recentemente, em dezembro de 2020, sendo um forte indicativo do interesse comercial sobre esse preciosa líquido. Entretanto, a Organização das Nações Unidas (ONU) reafirma o caráter de direito humano da água e a patente violação a eles caso ela venha ser tratada como um ativo qualquer na bolsa de valores em Wall Street ${ }^{47}$.

Nessa esteira, Rodell et al..$^{48}$ trabalham com a perspectiva de tratamento da questão hidrológica como um problema transfronteiriço, o que faz todo o sentido, sendo necessário um balanceamento da competição por água, das demandas de água, sendo preciso isso ser revisto urgentemente, pois trata-se de uma agenda fundamental, indicando uma verdadeira "tragédia dos comuns" em um contexto de competição oportunística pelas águas, notadamente, as subterrâneas. É preciso, talvez, um grande projeto planetário para que isso ocorra. Os pesquisadores ainda arrematam:

In many regions, crop irrigation on massive scales has been
supported by unsustainable rates of groundwater abstrac-
tion. In the face of aquifer depletion, population growth and
climate change, water and food security will depend upon

45 ELIAS, G. ¿Es posible una diplomacia de aguas en América Latina? Marco para una cooperación internacional en la gestión hídrica de cuencas transfronterizas. Anuario en Relaciones Internacionales, p. $11-$ 17, 2017.

46 PATEIRO, L. M.; SINDICO, F. El valor jurídico y práctico del proyecto de artículos de la CDI sobre el derecho de los acuíferos transfronterizos. ACDI, Bogotá, v. 13, p. 19-46, 2019.

47 ORGANIZAÇÃO DAS NAÇÕES UNIDAS. Comercializar el agua en el mercado de futuros de Wall Street viola los derechos bumanos. 2020. Disponível em: https://news.un.org/es/story/2020/12/1485432. Acesso em: 18 dez. 2020.

48 RODELL, M. et al. Emerging trends in global freshwater availability. Nature, v. 557, p. 651-659, 2018. water-saving technologies and improved management and governance $e^{49}$.

Portanto, a intenção é demonstrar uma ampla fundamentação para sustentar a tese de um acordo global em torno de uma proteção das águas compartilhadas para preservação da saúde e qualidade do meio ambiente e de todas as formas de vida existente no planeta, conforme, por exemplo, os dados apresentados no Gráfico 2.

Chama atenção a abordagem de Bruckmann que já inseria a água doce como um dos recursos naturais que se adequava, e se adéqua, a uma lógica de apropriação de bens comuns, em conjunto, também, com a produção de conhecimento científico e inovação. Assim ela apontou:

la disputa global por recursos minerales, recursos energé cos, ges- ón de la bio-diversidad, del agua y de los ecosistemas de cara a las nuevas ciencias, se desdobla en múl ples dimensiones polí cas, económicas y militares. Sin el desarrollo de un pensamiento estratégico que se a rme en el principio de la soberania y en una visión de futuro de largo plazo, los países la noamericanos y la comunidad de países en proceso de integración, enen menos condiciones de hacer frente a las enormes presiones generadas por esta situación de disputa, donde está en juego, en úl ma instancia, la capacidad de reorganización de proyectos hege- mónicos y la emergencia de proyectos contra-hegemónicos. ${ }^{50}$

Parece que não se trata de algo que se refere, unicamente, ao local, sendo imprescindível um pensamento de repercussões regionais e planetárias. É importante lembrar que Estados Unidos, Canadá, Reino Unido e Austrália foram contrários na Assembleia Geral da ONU, em 2010, a tornar o acesso à água potável e ao esgotamento tratado como direito humano. Isso teria diversas implicações para os governos, principalmente em não se transformar esses serviços em mercadorias pautadas por indicadores econômicos.

É importante refletir acerca do panorama planetário da água, não se pode ter a visão ingênua de que há uma dinâmica de forças de interesse apenas local, mas atores globais que se rearranjam no sentido de controlar e esta-

\footnotetext{
49 Em muitas regiões, a irrigação de culturas em grande escala tem sido apoiada por taxas insustentáveis de captação de águas subterrâneas. Diante do esgotamento dos aquíferos, o crescimento populacional e as mudanças climáticas, a água e a segurança alimentar dependerão de tecnologias de economia de água e de melhor gerenciamento e governança. RODELL, M. et al. Emerging trends in global freshwater availability. Nature, v. 557, p. 651-659, 2018. (Tradução livre).

50 Bruckmann, M. Recursos naturales y la geopolitica de la integración sudamericana. Instituto Perumundo; Fondo Editorial J.C.Mariátegui, 2012. p. 22.
} 
belecer processos de regulação da água ${ }^{51}$. Hoje o petróleo, por exemplo, sofre a ação de uma política de preços global, em franco processo de financeirização desse recurso, não sendo fantasioso pensar em algo semelhante para a água. Outrossim, nesse contexto é preciso considerar que a água é exportada de forma embutida na produção agrícola e na produção industrial em geral, de acordo com o conceito de água virtual. Isso implica a necessidade de se planejar a escassez hídrica em diversas regiões em virtude da sobre-exploração desse bem ${ }^{52}$.

Pode-se dividir essa questão em dois estratos. Um primeiro que defende a água como bem econômico, capaz de se transformar em uma commodity, submetido a uma política de preços e de mercado, apoiado pelo Banco Mundial que é um grande financiador de empresas de água e de esgotamento sanitário, em um modelo privado ou público-privado ${ }^{53}$. Desses setores de atuação, um deles é a água, esgotamento e resíduos, perfazendo um total de 37 projetos ativos relacionados com a área de água e esgotamento, além de 187 que se encerraram, com uma atuação majoritária em países em desenvolvimento e pobres $^{54}$. O segundo estrato é formado pelo conjunto de setores que entendem o acesso à água como um direito humano inalienável defendido por movimentos sociais, intelectuais e outros atores que estão articulados na defesa da água como bem da humanidade.

Figura 2 - mapa que demonstra a potencialidade das águas subterrâneas no Planeta



Fonte: UNESCO ${ }^{55}$.

\footnotetext{
51 Bruckmann, M. Recursos naturales y la geopolitica de la integración sudamericana. Instituto Perumundo; Fondo Editorial J.C.Mariátegui, 2012.

52 CASTRO, Douglas de. Escassez hídrica e direito internacional econômico: o Brasil como protagonista na transferência de água para regiões áridas. Revista de Direito Internacional, Brasília, v. 13, n. 1, p. 214-227, 2016.

53 http://projects.worldbank.org/sector?lang=en\&page=

54 THE WORLD BANK. Recently approved projects. Disponível em: http://projects.worldbank.org/search?lang=en\&searchTerm=\&sec torcode_exact=WC Acesso em: 13 abr. 2021.

55 UNESCO. Atlas of transboundary aquifers: global maps, regional
}

$\mathrm{Na}$ figura 2, demonstra-se que a disputa em face da água é possível, já que alguns mananciais de águas subterrâneas e superficiais estão inseridos em dois ou mais países, conforme figuras 1 e 5 . Muitos desses aquíferos são fundamentais no ciclo hidrológico, sendo importantes para a manutenção de rios, fornecimento de água ao meio urbano e rural. Como se isso não fosse suficiente, exercem papel central para a manutenção de diversos ecossistemas, como pântanos e outros presentes nas bacias hidrográficas. É uma riqueza invisível ao olhar, principalmente, daqueles que vivem nas cidades imersos em outra dinâmica. Na figura 3, vê-se o nível de extração das águas subterrâneas principalmente pelas atividades agrícolas, caminho que resulta em estresse hídrico compartilhado com diversas nações.

Na figura 3, também é possível verificar uma desigualdade na demanda por água para agricultura entre norte e sul do globo. Países como Estados Unidos da América, Índia, Paquistão, China respondem por uma parcela considerável dessa extração, cuja mudança de paradigma certamente não ocorrerá enquanto não houver uma mudança no modelo de desenvolvimento transformando a água em um bem estratégico para a manutenção da vida, porque, geopoliticamente, ele já é estratégico entre os países. Bruckmann chama atenção para a pressão dos Estados Unidos sobre os recursos hídricos, inclusive tendo já contaminado importantes reservatórios como os grandes lagos e a existência de cidades como Las Vegas que demandam, cada vez mais, água para o turismo ${ }^{56}$. A Ásia está despontando em nível de uso dessas águas subterrâneas, assim como os Estados Unidos da América e a Europa, destacando-se o uso intensivo para a agricultura, geralmente, para exportação. O continente africano tem um perfil mais agrícola, mantendo esse uso alto para a agricultura. Porém isso se repete em quase a totalidade dos continentes, à exceção da Europa, cujo uso é maior nas cidades.

A possibilidade de solução partiria, certamente, da política e do estabelecimento de marcos jurídicos internacionais acerca do uso da água, dando continuidade ao estabelecimento da água como direito humano, bem como ambientalmente relevante, desconstruindo a ideia de que a solução seria tornar a água um bem econômico. Porém, isso seria uma tese com remotíssimas

cooperation and local inventories. Paris: UNESCO, 2009.

56 Bruckmann, M. Recursos naturales y la geopolitica de la integración sudamericana. Instituto Perumundo; Fondo Editorial J.C.Mariátegui, 2012. 
chances de acontecer, uma vez que os mapas nas figuras destacam a irregular distribuição e uso dessas águas pelos países e regiões concentradores da industrialização e inovação no globo e a destinação para a produção em larga escala na agricultura de exportação. Portanto, o uso e acesso à água é uma questão que deve ser tratada no âmago do direito internacional diante da sua relevância para todos os povos.

Figura 3 - mapa que destaca o uso da água subterrânea pela agricultura

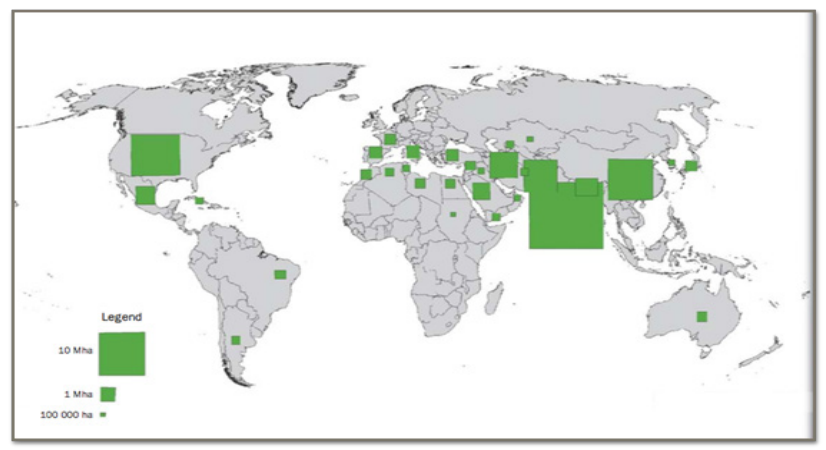

Fonte: UNESCO ${ }^{57}$.

Outra preocupação em relação à água se relaciona à recarga desses aquíferos destacados neste artigo, cujo processo faz parte do ciclo hidrológico, e se constituem em grandes reservatórios para o futuro incerto da humanidade ${ }^{58}$. Na figura 4, posiciona-se essa questão da recarga como um elemento necessário ao planejamentos e à governança internacional da água, não sendo algo que depende, apenas, de uma nação, sendo fundamental para o ciclo da água no planeta, interferindo, diretamente, no fluxo de água nos rios, nas lagoas, nos pântanos e em outros ecossistemas complexos, principalmente em relação ao processo de mudanças climáticas. Esses elementos são fundantes para um planejamento macro acerca dos recursos hídricos e, por consequência, há coleta das águas utilizadas, seu tratamento e devolução ao meio ambiente.

\footnotetext{
57 UNESCO. Atlas of transboundary aquifers: global maps, regional cooperation and local inventories. Paris: UNESCO, 2009.

58 Bruckmann, M. Recursos naturales y la geopolitica de la integración sudamericana. Instituto Perumundo; Fondo Editorial J.C.Mariátegui, 2012.
}

Figura 4 - mapa dos aquíferos com maior eficiência na recarga

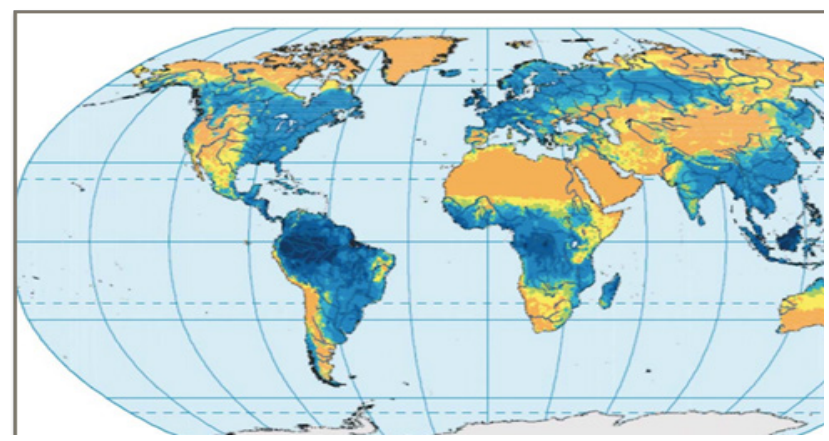

Fonte: UNESCO ${ }^{59}$.

$\mathrm{Na}$ figura 4, revela-se a importância estratégica que tem a América Latina para a geopolítica da água, sua alta capacidade de recarga coloca-a em um nível alto de relevância, o que demanda ações regionais no sentido de uma governança transnacional da água. Essa figura, analisada a partir dos estudos de Rodell et al..$^{60}$, indica que essas regiões já sofrem os efeitos diretos das mudanças climáticas, principalmente por sua interferência no regime de chuva e, por conseguinte, no ciclo hidrológico que reabastece os reservatórios. Esse processo de transformação ambiental, somado ao aumento do consumo de água nas cidades, a produção de alimentos em larga escala, a poluição dos rios, a poluição dos mares, a falta de tratamento e não reutilização das águas de esgoto, enfim, resultaria num colapso da humanidade. Com base na medição do nível de precipitação no Planeta, uso da água e outras variáveis, os pesquisadores assim demarcaram a seguinte necessidade:

data provide motivation for multilateral cooperation among nations, states and stakeholders, including development of transboundary water-sharing agreements, to balance competing demands and defuse potential conflict. Government policies that incentivize water conservation could help to avert a 'tragedy of the commons' scenario, that is, opportunistic competition for groundwater outweighing the altruistic impulse to preserve the resource $e^{61}$.

\footnotetext{
59 UNESCO. Atlas of transboundary aquifers: global maps, regional cooperation and local inventories. Paris: UNESCO, 2009.

${ }^{60}$ RODELL, M. et al. Emerging trends in global freshwater availability. Nature, v. 557, p. 651-659, 2018.

${ }^{61}$ Os dados fornecem motivação para a cooperação multilateral entre nações, estados e partes interessadas, incluindo o desenvolvimento de acordos transfronteiriços de compartilhamento de água, para equilibrar as demandas concorrentes e neutralizar possíveis conflitos. As políticas governamentais que incentivam a conservação da água podem ajudar a evitar um cenário de „tragédia dos comuns”, isto é, a concorrência oportunista pelas águas subterrâneas, superando o impulso altruísta de preservar o recurso. RODELL, M. et al. Emerging trends in global freshwater availability. Nature, v. 557, p.
} 
Portanto, as pesquisas apontam que a gestão da água deve ocorrer em diversas frentes. De um lado, há o consumo excessivo na irrigação das lavouras, sendo necessário outro modelo que seja sustentável, e, de outro, cidades crescendo nas franjas dos aquíferos e rios, consolidando-se um cenário, como já mencionado, de crises, podendo ser mitigado por meio da governança internacional aliada à tecnologia.

Figura 5 - Mapa das bacias hidrográficas transfronteiriças do mundo

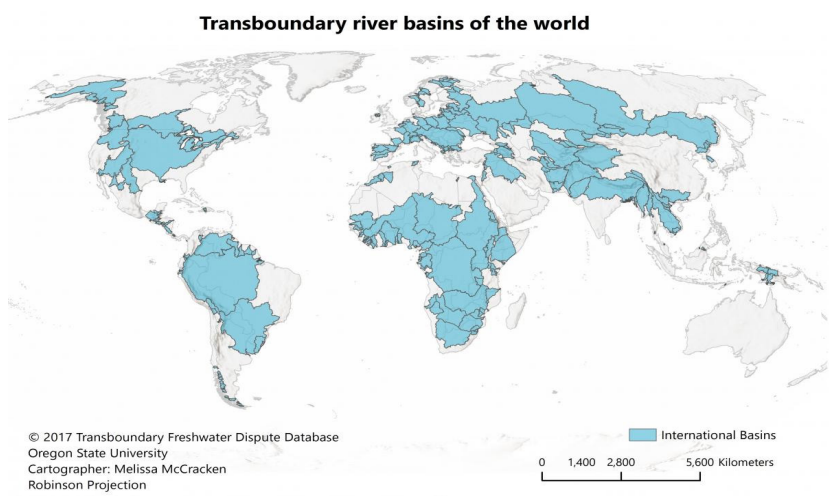

Fonte: https:/ / transboundarywaters.science.oregonstate.edu/content/data-and-datasets

Ao se visualizar o mapa da figura 5 , é preciso ter um olhar crítico e problematizador acerca das potenciais disputas entre países pela água, para geração de energia, para transporte, para o consumo, para a pesca, enfim, diversos os usos e, portanto, possibilidades latentes de conflitos internacionais. $\mathrm{Na}$ figura 6 , há distribuição de tratados e acordos bilaterais, que são maioria, e multilaterais de uso e acesso às águas transfronteiriças, o que pode ser comparado à figura 5 , verificando-se que, em boa parte do Planeta, ainda não há uma governança internacional da água compartilhada.

Figura 6 - mapeamento dos tratados e acordos em torno do uso e acesso à águas transfronteiriças.

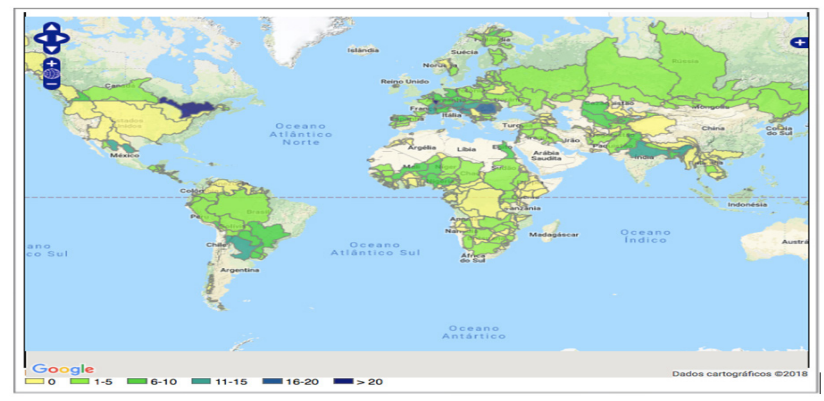

Fonte: https://transboundarywaters.science.oregonstate.edu/content/data-and-datasets

651-659, 2018. (Tradução livre).
Isso reforça a importância, em relação aoDireito Internacional, de um protagonismo diplomático mais eficiente em torno de uma hidrodiplomacia, que será definida mais adiante, em virtude das lacunas regulatórias internacionais ainda existentes e a quantidade de água que se tem acesso. Wolf et al. apontam que a crise hídrica no planeta é de governança e que a tarefa mais desafiadora é a distribuição da água e sua universalização ${ }^{62}$.

Os dados coletados de 1820 até 2007 apresentam que há uma pluralidade de documentos internacionais que regulam o uso das águas, porém verificando aqueles referentes ao século XX houve a subscrição de 145 tratados vinculados aos recursos hídricos transfronteiriços, destes 124 são bilaterais e apenas 21 multilaterais. Em relação à natureza dos mesmos, 53 são referentes ao fornecimento de água, 57 à produção de energia hidroelétrica, 3 sobre controle de inundações, 9 sobre usos industriais, 6 referentes à navegação e 1 sobre o sistema de pesca ${ }^{63}$. A governança das águas transfronteiriças ocorre sob unidades e conceitos que estão dispostos no quadro 1, que são estruturantes para compreender de que forma pode-se operacionalizar juridicamente as águas transfronteiriças.

Quadro 1 - diferentes conceitos relacionados com água transfronteiriça ou compartilhadas

\begin{tabular}{|l|l|l|}
\hline Conceito & $\begin{array}{l}\text { Instrumento } \\
\text { jurídico }\end{array}$ & Definição \\
\hline $\begin{array}{l}\text { Bacia hidro- } \\
\text { gráfica in- } \\
\text { ternacional }\end{array}$ & $\begin{array}{l}\text { Regras de Hel- } \\
\text { sinki (1966) }\end{array}$ & $\begin{array}{l}\text { Zona geográfica } \\
\text { que se estende } \\
\text { pelo território } \\
\text { de dois ou mais } \\
\text { Estados e está de- } \\
\text { marcada pela linha } \\
\text { divisória de um } \\
\text { sistema hidrográfi- } \\
\text { co de águas super- } \\
\text { ficiais e frenéticas } \\
\text { que fluem até uma } \\
\text { saída comum. }\end{array}$ \\
\hline
\end{tabular}

${ }^{62}$ WOLF, A. T. et al. Water governance benchmarking: concepts and approach framework as applied to Middle East and North Africa countries. Water Policy n. 16, p. 1121-1139, 2014.

63 TRANSBOUNDARY FRESHWATER DISPUTE DATABASE. International Freshwater Treaties (by River Basin). Disponível em: http://gis.nacse.org/tfdd/treaties.php Acesso em: 13 abr. 2021. 


\begin{tabular}{|l|l|l|}
\hline Conceito & $\begin{array}{l}\text { Instrumento } \\
\text { jurídico }\end{array}$ & Definição \\
\hline $\begin{array}{l}\text { Águas } \\
\text { teiriças }\end{array}$ & $\begin{array}{l}\text { Convênio da } \\
\text { CEPE de 1992 } \\
\text { (Convenção de } \\
\text { Helsinki), art. 1 }\end{array}$ & $\begin{array}{l}\text { Águas superficiais } \\
\text { ou freáticas que } \\
\text { apontam, atraves- } \\
\text { sam ou se encon- } \\
\text { tram situados nas } \\
\text { fronteiras de dois } \\
\text { ou mais Estados. }\end{array}$ \\
\hline $\begin{array}{l}\text { Curso de } \\
\text { água }\end{array}$ & $\begin{array}{l}\text { Convenção } \\
\text { sobre o direito } \\
\text { dos usos dos } \\
\text { nursos de água } \\
\text { internacionais } \\
\text { para fins distin- } \\
\text { tos da nave- } \\
\text { gação de 1997, } \\
\text { art. 1 }\end{array}$ & $\begin{array}{l}\text { Sistema de águas } \\
\text { de superfície e } \\
\text { subterrâneas que, } \\
\text { em virtude de } \\
\text { suas relação física, } \\
\text { constituem um } \\
\text { conjunto unitário } \\
\text { e normalmente } \\
\text { fluem a uma de- } \\
\text { sembocadura co- } \\
\text { mum. }\end{array}$ \\
\hline $\begin{array}{l}\text { Aqüífero } \\
\text { transfrontei- } \\
\text { riço }\end{array}$ & $\begin{array}{l}\text { Resolução da } \\
\text { Assembléia Ge- } \\
\text { ral das Nações } \\
\text { Unidas sobre } \\
\text { o direito dos } \\
\text { aquíferos tran- } \\
\text { sfronteiriços A/ } \\
\text { RES/63/124 } \\
\text { de 2009, art. 2 }\end{array}$ & $\begin{array}{l}\text { Aqǘro: for- } \\
\text { mação geológica } \\
\text { permeável porta- } \\
\text { dora de água, situa- } \\
\text { da sobre uma capa } \\
\text { menos permeável, } \\
\text { e a água contida na } \\
\text { zona saturada da } \\
\text { formação. Sistema } \\
\text { aqüífero: uma série } \\
\text { de dois ou mais } \\
\text { aquíferos que estão } \\
\text { conectados hidrau- } \\
\text { licamente. }\end{array}$ \\
\hline
\end{tabular}

Fonte: Baseado em SANCHÉZ et al. ${ }^{64}$

A operacionalização desses conceitos é fundamental para desenhar um modelo de governança que seja efetivamente democrático, tendo como pressuposto o controle social, a participação das comunidades influenciadas por essas águas, com a presença do poder público e outros atores. Alba permite enxergar muito mais além do que uma questão meramente técnica, sendo na verdade uma questão política, que envolve atores, forças e pressões antagônicas, sendo traços de uma hidropolítica

${ }^{64}$ SÁNCHEZ, J. C. et al. El derecho internacional de aguas en América Latina: manual de capacitación. Montevideo: GWP Sudamérica, 2015. e, segundo ela, este concepto nos permite situar el conjunto de condiciones de una disputa por el agua entendiéndola como recurso geopolítico ${ }^{65}$. Coaduna-se com os elementos já mencionados, na medida em que se tem a percepção clara de uma crise de acesso à água e que sua distribuição não é equânime, conforme dados do quadro 2.

Quadro 2 - média do consumo de água em litros per capita por dia por país

\begin{tabular}{|l|c|}
\hline Estados Unidos & 575 \\
\hline Austrália & 493 \\
\hline Noruega & 301 \\
\hline França & 287 \\
\hline Suécia & 195 \\
\hline Brasil & $150(2011)^{*}$ \\
\hline Rio de Janeiro & $189(2011)^{*}$ \\
\hline Mato Grosso & $168(2011)^{*}$ \\
\hline São Paulo & $177(2011)^{*}$ \\
\hline Reino Unido & 149 \\
\hline Índia & 135 \\
\hline China & 86 \\
\hline Nigéria & 36 \\
\hline Etiópia & 15 \\
\hline Angola & 15 \\
\hline Moçambique & 4 \\
\hline
\end{tabular}

Fonte: http://memoria.ebc.com.br/agenciaBrazil/noticia/2011-09-11/consumo-de-agua-por-habitante-noBrazil-e-estavel.

Com base na figura 7 e no gráfico 1, fica patente a necessidade de uma estratégia política global baseada em modelo de governança que privilegie a distribuição de recursos de maneira justa, praticando-se uma verdadeira justiça hídrica, com foco na sustentação dos ecossistemas e sobrevivência humana.

${ }_{65}$ ALBA, F. de. Geopolítica del agua en México: la oposición entre la hidropolítica y el conflicto sociopolítico. Los nuevos rostros de las "luchas" sociales. Revista Internacional de Desenvolvimento Local, v. 8, n. 1, p. 95-112, mar. 2007. p. 100. 
Figura 7 - estresse hídrico por países em 2013. Relação \% de retirada versus oferta renovável. Níveis de estresse: baixo (bege), baixo a médio (amarelo); médio a alto (laranja); alto (vermelho); extremamente alto (vermelho escuro)

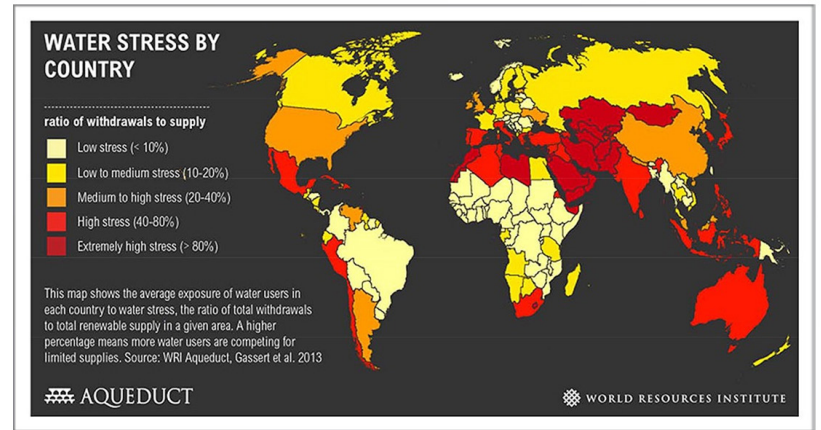

Fonte: World Resources Institute ${ }^{66}$.

Gráfico 1 - os dez países com mais recursos hídricos renováveis (sem contar os aquíferos)

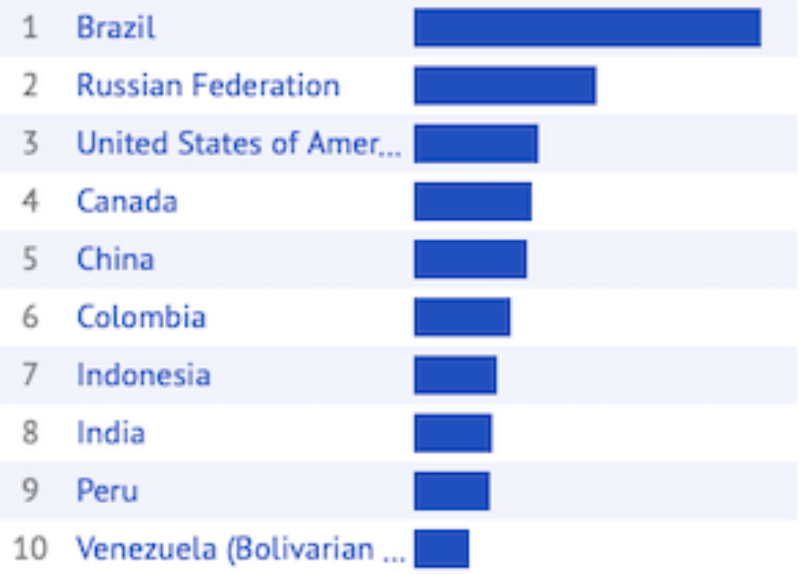

Fonte: World Data Atlas ${ }^{67}$.

No gráfico 1, aponta-se o quão estratégico é o Brasil na América Latina frente à potencialidade concreta de recursos hídricos, indicando a necessidade de uma governança hídrica representada em uma hidrodiplomacia especializada que compreenda os fatores para a negociação dos múltiplos usos das águas nas fronteiras desses países. No gráfico 1, reforça-se, mais ainda, a relevância de uma governança hídrica internacional forte.

\footnotetext{
66 WORLD RESOURCES INSTITUTE. World's 36 Most WaterStressed Countries. 2013. Disponível em: https://www.wri.org/insights/worlds-36-most-water-stressed-countries. Acesso em: 12 dez. 2020.

67 WORLD DATA ATLAS. Total Renewable Water Resources. 2017. Disponível em: https://knoema.com/atlas/topics/Water/TotalRenewable-Water-Resources/Renewable-water-resources. Acesso em: 16 abr. 2021.
}

Diante dessa realidade de crise e de complexidade, Hernández Ulate et al. menciona o seguinte:

La gobernabilidad se define como "la capacidad del sistema
social democrático de autogobernarse y ser capaz. de enfrentar
positivamente los retos y las oportunidades nacionales, regio-
nales y globales" (GWP y BID, 2003:20). En el caso de
los recursos hidricos, esta definición implica que la sociedad
se prepare para asumir la responsabilidad de convertirse en
gestora de este recurso y garantizar su sostenibilidad y la del
sistema natural donde se encuentra. ${ }^{68}$

É básica, em um processo de governança hídrica, a criação de uma institucionalidade e a articulação entre atores interessados, de modo que se mitiguem eventuais desequilibrios. Hernández Ulate reforça esse processo:

La gobernabilidad de las cuencas internacionales debe con-
siderar, nece-sariamente, la emergente institucionalidad en
forma de Comisiones de Cuencas y la colaboración activa de
los actores locales en el manejo de los recursos naturales en
estos sistemas naturales transfronterizos. ${ }^{69}$

$\mathrm{Na}$ Carta da Terra $^{70}$ escrita em 2000, com a mediação da Organização das Nações Unidas (ONU), apresentaram-se alguns princípios que podem ser utilizados para a implantação de processos de governança internacional da água:

1) integridade ecológica das bacias hidrográficas internacionais - os planos de manejo devem contemplar e reconhecer a bacia hidrográfica como um bloco só a ser gerenciado e não de forma compartimentalizada, planejando de forma integrada, conjunta a sustentabilidade dos recursos desse território, inclusive implementando formas de resolução de conflitos;

68 A governança é definida como "a capacidade do sistema social democrático de se governar e de ser capaz de enfrentar positivamente desafios e oportunidades nacionais, regionais e globais". No caso dos recursos hídricos, essa definição implica que a sociedade esteja preparada para assumir a responsabilidade de se tornar um administrador desse recurso e garantir sua sustentabilidade e a do sistema natural em que está localizado. HERNÁNDEZ ULATE, A.; RAMÍREZ, A. L.; ELIZONDO, A. J. Gobernabilidad e instituciones en las Cuencas Transfronterizas de América Central y México. San José, C.R.: FLACSO, 2009. p. 97. (Tradução livre).

${ }^{69}$ A governança de bacias internacionais deve necessariamente considerar a estrutura institucional emergente na forma de Comissões de Bacia e a colaboração ativa de atores locais na gestão de recursos naturais nesses sistemas naturais transfronteiriços. HERNÁNDEZ ULATE, A.; RAMÍREZ, A. L.; ELIZONDO, A. J. Gobernabilidad e instituciones en las Cuencas Transfronterizas de América Central y México. San José, C.R.: FLACSO, 2009. p. 133. (Tradução livre).

70 THE EARTH CHARTER INTERNATIONAL. La Carta de la Tierra +15 celebraciones y otros eventos en México. 2015. Disponível em: http://cartadelatierra.org/descubra/la-carta-de-la-tierra/ Acesso em: 13 abr. 2021. 
2) Transformação do enfoque setorial - isso significa que as instituições deverão trabalhar de forma articulada, inclusive incorporando o problema hídrico como uma questão que atinge a todos, portanto, a articulação institucional é fundamental em detrimento da setorização;

3) Conscientização social, transformação e participação - a sociedade deverá se apropriar dos processos de regulação, de controle e gestão dos recursos hídricos e, para isso, os instrumentos de informação são essenciais no processo de transformação dos procedimentos da sociedade;

4) Marco legal e situação atual do recurso água - a água sofreu impactos severos que devem ser abordados pela legislação. Os princípios da Convenção de Nova York devem ser considerados dentro das legislações nacionais, uma vez que oferecem, no caso das bacias internacionais do México e da América Central, elementos fundamentais para a governança e a gestão ambiental. Estas se baseiam na integralidade dos sistemas hídricos e contam com o reconhecimento das seções que correspondem, territorialmente, a cada país, compartilhando a equidade de direitos, abrindo as possibilidades de negociação de usos e possibilitando um equilíbrio entre interesses e necessidades de cada país em uma bacia internacional;

5) Novas instituições de bacias e sistemas hidrográficos internacionais - é preciso reconhecer novas institucionalidades surgidas espontaneamente na sociedade, inclusive um reconhecimento jurídico em decretos e leis.

Saguier et al..$^{71}$ apresentam os motivos pelos quais ainda se pode classificar como insuficiente na prática uma governança internacional de bacia(s), destacando os seguintes entraves: ajuste insuficiente entre os arranjos de governança institucional, os processos socioecológicos, decisões de cima para baixo e fragmentação jurisdicional cobrindo seções discretas da bacia. Facilitar a troca de saberes e informações e interconectar as escalas de governança são fundamentais para a gestão de bens ambientais como a água ${ }^{72}$. Pragmaticamente,

\footnotetext{
71 SAGUIER, M. et al. Interdisciplinary research networks and science-policy-society interactions in the Uruguay River Basin. Environmental Development, n. 38, 2021. Disponível em: https:/ /www.sciencedirect.com/science/article/pii/S2211464520301330?via\%3Dihub Acesso em: 14 abr. 2021.

72 SILVA, J. I. A. O. Public access to information for sustainable development. In: LEAL FILHO, W. et al. (ed.) Peace, Justice and Strong
}

defende-se uma interação maior entre ciência, políticas e sociedade.

\subsection{Sistema normativo de gestão e governança das águas transfronteiriças: a necessidade de uma hidrodiplomacia}

$\mathrm{Na}$ presente pesquisa, adotou-se como estratégia verificar, nos documentos internacionais, principais fundamentos para se protegerem, internacionalmente, os mananciais de água transfronteiriços ou não. Porém, quanto aos primeiros, trata-se de algo mais delicado e envolve atores de diversas nações. Sendo assim, produziu-se o quadro 3 como forma de visualizar-se melhor o contexto internacional que suporte fundamentações dentro do direito internacional público contemporâneo.

Quadro 3 - fundamentação legal internacional para a proteção das águas doce compartilhadas

\begin{tabular}{|l|l|}
\hline \multicolumn{1}{|c|}{$\begin{array}{c}\text { Documento } \\
\text { internacional }\end{array}$} & \multicolumn{1}{|c|}{ Fundamentação } \\
\hline $\begin{array}{l}\text { Declaração } \\
\text { de Estocolmo } \\
(1972)\end{array}$ & $\begin{array}{l}\text { PRINCíPIO 2. Os recursos na- } \\
\text { turais da terra, incluindo ar, água, } \\
\text { solo, flora e fauna e, especialmen- } \\
\text { te, amostras representativas de } \\
\text { ecossistemas naturais, devem ser } \\
\text { preservados para o benefício das } \\
\text { gerações presentes e futuras, por } \\
\text { meio de planejamento ou manejo } \\
\text { cuidadoso, segundo convenha. }\end{array}$ \\
\hline $\begin{array}{l}\text { Convenção } \\
\text { sobre as zonas } \\
\text { úmidas - con- } \\
\text { venção Ramsar } \\
(1971-1975)\end{array}$ & $\begin{array}{l}\text { áreas úmidas são áreas de pântano, } \\
\text { poça, turfa ou água, natural ou ar- } \\
\text { tificial, permanente ou temporária, } \\
\text { com água estagnada ou corrente, } \\
\text { doce, salobra ou salgada, incluindo } \\
\text { áreas de água do mar, com menos } \\
\text { de seis metros de profundidade na } \\
\text { maré baixa. }\end{array}$ \\
\hline
\end{tabular}

Institutions: encyclopedia of the UN Sustainable Development Goals. New York: Springer, 2021. 


\begin{tabular}{|c|c|}
\hline $\begin{array}{c}\text { Documento } \\
\text { internacional }\end{array}$ & Fundamentação \\
\hline $\begin{array}{l}\text { Acordo relacio- } \\
\text { nado sobre à } \\
\text { proteção mun- } \\
\text { dial, cultural e } \\
\text { natural (1972) }\end{array}$ & $\begin{array}{l}\text { Art. } 2 \text { “ara os fins deste Acordo, } \\
\text { considera-se patrimônio natural: } \\
\text { - os monumentos naturais con- } \\
\text { stituídos por formações físicas } \\
\text { e biológicas ou grupos dessas } \\
\text { formações, com valor universal } \\
\text { excepcional do ponto de vista } \\
\text { estético ou científico; } \\
\text { - formações geológicas e fisio- } \\
\text { gráficas e áreas claramente deli- } \\
\text { mitadas que constituem o habitat } \\
\text { de espécies animais e vegetais } \\
\text { ameaçadas e que têm valor univer- } \\
\text { sal excepcional do ponto de vista } \\
\text { da ciência ou da conservação; } \\
\text { Destaques naturais ou áreas natu- } \\
\text { rais claramente delimitadas, de va- } \\
\text { lor universal excepcional do ponto } \\
\text { de vista da ciência, conservação ou } \\
\text { beleza natural. }\end{array}$ \\
\hline $\begin{array}{l}\text { Encontro do } \\
\text { Rio de Janeiro } \\
\text { (1992) - con- } \\
\text { venção da bio- } \\
\text { diversidade }\end{array}$ & $\begin{array}{l}\text { Cientes de que a conservação e } \\
\text { o uso sustentável da diversidade } \\
\text { biológica são essenciais para aten- } \\
\text { der às necessidades de alimentação, } \\
\text { saúde e outras necessidades da } \\
\text { crescente população mundial, para } \\
\text { a qual o acesso a recursos genéti- } \\
\text { cos e tecnologias são essenciais, } \\
\text { e participação nesses recursos e } \\
\text { tecnologias, }\end{array}$ \\
\hline $\begin{array}{l}\text { Encontro do } \\
\text { Rio de Janeiro } \\
\text { (1992) - con- } \\
\text { venção da } \\
\text { biodiversidade } \\
\text { - Convenção } \\
\text { quadro-quadro } \\
\text { sobre mudanças } \\
\text { climáticas }\end{array}$ & $\begin{array}{l}\text { "Efeitos adversos das mudanças } \\
\text { climáticas" referem-se a mudanças } \\
\text { no ambiente físico ou biota resul- } \\
\text { tantes das mudanças climáticas } \\
\text { que têm efeitos adversos signifi- } \\
\text { cativos na composição, resiliência } \\
\text { ou produtividade de ecossistemas } \\
\text { naturais ou gerenciados, ou no } \\
\text { funcionamento dos sistemas socio- } \\
\text { econômicos, ou na saúde e bem- } \\
\text { estar humanos. }\end{array}$ \\
\hline
\end{tabular}

\section{Documento internacional}

Encontro do

Rio de Janeiro

(1992) - decla-

ração sobre $o$

meio ambiente

e desenvolvi-

mento

Encontro do

Rio de Janeiro

(1992) - agen-

da 21

\section{Fundamentação}

Os Estados devem cooperar em

um espírito de solidariedade glo-

bal para conservar, proteger e

restaurar a saúde e integridade do

ecossistema da Terra. Por terem

contribuído para diferentes graus

de degradação ambiental global,

os Estados têm responsabilidades

comuns, porém diferenciadas. Os

países desenvolvidos reconhecem

sua responsabilidade na busca in-

ternacional pelo desenvolvimento

sustentável, considerando-se as

pressões que suas sociedades exer-

cem sobre o meio ambiente global

e as tecnologias e recursos finan-

ceiros de que dispõem.

Proteção dos recursos hídricos, qualidade da água e ecossistemas aquáticos. As montanhas são uma importante fonte de água, energia e diversidade biológica. Abastecimento de água e saneamento para os pobres rurais que carecem desses serviços: (...) promover o acesso da comunidade à propriedade dos serviços de abastecimento de água e saneamento e direitos sobre eles; fortalecer o setor de abastecimento de água e saneamento nas áreas rurais (...) Adotar tecnologias adequadas de tratamento de água; levar em consideração os aspectos de quantidade e qualidade da água. Deve-se reconhecer a natureza multissetorial do uso dos recursos hídricos no contexto do desenvolvimento socioeconômico, bem como a utilização desses recursos para fins múltiplos como abastecimento de água e saneamento, agricultura, indústria, desenvolvimento urbano, geração de energia hidrelétrica, pesca interior, transporte, atividades recreativas, gestão de terras baixas e planícies e outras atividades. 


\begin{tabular}{|c|c|}
\hline & Fundamentação \\
\hline & $\begin{array}{l}\text { Os recursos de água doce são um } \\
\text { componente essencial da hidrosfera } \\
\text { da Terra e uma parte indispensável } \\
\text { de todos os ecossistemas terrestres. } \\
\text { Tratar as águas residuais municipais } \\
\text { para seu uso seguro na agricultura e } \\
\text { aquicultura; Controlar as descargas } \\
\text { de resíduos industriais, utilizando, } \\
\text { entre outras, técnicas de produção } \\
\text { que gerem poucos resíduos e técni- } \\
\text { cas de recirculação de água, de forma } \\
\text { integrada e através da aplicação de } \\
\text { medidas cautelares derivadas de uma } \\
\text { análise exaustiva do ciclo de vida; } \\
\text { Monitore a qualidade da água (...) } \\
\text { reabilitar corpos d’água contamina- } \\
\text { dos ou degradados para restaurar ha- } \\
\text { bitats e ecossistemas aquáticos; (...) } \\
\text { O abastecimento de água potável e o } \\
\text { saneamento ambiental são vitais para } \\
\text { proteger o meio ambiente, melhorar } \\
\text { a saúde e reduzir a pobreza. Pro- } \\
\text { teção à saúde pública, tarefa que não } \\
\text { só exigirá o abastecimento de água } \\
\text { potável livre de germes patogênicos, } \\
\text { mas também o combate aos vetores } \\
\text { de doenças no meio aquático. A água } \\
\text { doce é um recurso indivisível. O uso } \\
\text { de longo prazo dos recursos de água } \\
\text { doce do mundo requer gestão global } \\
\text { e reconhecimento da inter-relação } \\
\text { dos elementos relacionados à água } \\
\text { doce e sua qualidade. Ainda exi- } \\
\text { stem muitas doenças transmissíveis } \\
\text { importantes para as quais são abso- } \\
\text { lutamente necessárias medidas de } \\
\text { controle ambiental, especialmente } \\
\text { na área de abastecimento de água e } \\
\text { saneamento. Essas doenças são cóle- } \\
\text { ra, doenças diarreicas, leishmaniose, } \\
\text { malária e esquistossomose. }\end{array}$ \\
\hline
\end{tabular}

\begin{tabular}{|c|c|}
\hline $\begin{array}{c}\text { Documento } \\
\text { internacional }\end{array}$ & Fundamentação \\
\hline $\begin{array}{l}\text { Encontro do } \\
\text { Rio de Janeiro } \\
\text { (1992) - qua- } \\
\text { dro sobre mu- } \\
\text { danças climáti- } \\
\text { cas }\end{array}$ & $\begin{array}{l}\text { Proteger o sistema climático para o } \\
\text { benefício das gerações presentes e } \\
\text { futuras (Artigo 3.1); } \\
\text { Programas nacionais e regionais } \\
\text { com medidas para mitigar as mu- } \\
\text { danças climáticas (artigo 4, 1, b); } \\
\text { Tecnologias e processos práticos } \\
\text { que controlam, reduzem ou evitam } \\
\text { as emissões antropogênicas de ga- } \\
\text { ses de efeito estufa (Artigo 4, 1, c). } \\
\text { cooperar na preparação para a } \\
\text { adaptação aos impactos das alte- } \\
\text { rações climáticas e nos planos de } \\
\text { gestão das zonas costeiras, dos } \\
\text { recursos hídricos e da agricultura e } \\
\text { na proteção e recuperação das re- } \\
\text { giões afetadas pela seca e desertifi- } \\
\text { cação, bem como pelas inundações } \\
\text { (Artigo } 4,1 \text { ). }\end{array}$ \\
\hline $\begin{array}{l}\text { Convenção } \\
\text { internacional de } \\
\text { combate à de- } \\
\text { sertificação nos } \\
\text { países afetados } \\
\text { por seca grave } \\
\text { e/ou desertifi- } \\
\text { cação (1996) }\end{array}$ & $\begin{array}{l}\text { Âmbito: combate à desertificação } \\
\text { e mitigação dos efeitos da seca em } \\
\text { países afetados por seca severa e / } \\
\text { ou desertificação (art. 2.1). } \\
\text { Aplicação nas áreas afetadas de } \\
\text { estratégias integradas de longo pra- } \\
\text { zo baseadas no aumento da produ- } \\
\text { tividade da terra e na reabilitação, } \\
\text { conservação e gestão sustentada } \\
\text { da terra e dos recursos hídricos, a } \\
\text { fim de melhorar as condições de } \\
\text { vida, particularmente em nível das } \\
\text { comunidades locais (art. 2.2). }\end{array}$ \\
\hline $\begin{array}{l}\text { Declaração do } \\
\text { milênio (2000) }\end{array}$ & $\begin{array}{l}\text { reduzir pela metade a porcentagem } \\
\text { de pessoas que não têm acesso a } \\
\text { água potável ou que não podem } \\
\text { pagar por ela. }\end{array}$ \\
\hline
\end{tabular}




\begin{tabular}{|c|c|}
\hline $\begin{array}{c}\text { Documento } \\
\text { internacional }\end{array}$ & Fundamentação \\
\hline $\begin{array}{l}\text { Encontro } \\
\text { mundial de } \\
\text { Johannesburgo } \\
(2002)\end{array}$ & $\begin{array}{l}\text { O ambiente global continua se } \\
\text { deteriorando. A perda de biodi- } \\
\text { versidade continua; os estoques de } \\
\text { peixes continuam diminuindo; a } \\
\text { desertificação avança, reivindican- } \\
\text { do, cada vez mais, terras férteis; } \\
\text { os efeitos adversos das mudanças } \\
\text { climáticas já são evidentes; os desa- } \\
\text { stres naturais são mais frequentes } \\
\text { e mais devastadores e os países } \\
\text { em desenvolvimento tornaram-se } \\
\text { mais vulneráveis, enquanto a polu- } \\
\text { ição do ar, da água e dos oceanos } \\
\text { continua a privar milhões de seres } \\
\text { humanos de uma vida decente. }\end{array}$ \\
\hline $\begin{array}{l}\text { Assembléia Ge- } \\
\text { ral das Nações } \\
\text { Unidas (2010), } \\
\text { Resolução n. } \\
64 / 292\end{array}$ & $\begin{array}{l}\text { afirma que o acesso à água limpa e } \\
\text { segura e ao saneamento adequado } \\
\text { é um direito humano, essencial } \\
\text { para o pleno gozo da vida e outros } \\
\text { direitos humanos. }\end{array}$ \\
\hline Rio +20 (2012) & $\begin{array}{l}\text { Reconhecemos que a água é um } \\
\text { elemento básico do desenvol- } \\
\text { vimento sustentável, pois está } \\
\text { intimamente ligada a uma série } \\
\text { de desafios globais fundamentais. } \\
\text { Reiteramos, portanto, que é impor- } \\
\text { tante integrar os recursos hídricos } \\
\text { ao desenvolvimento sustentável e } \\
\text { enfatizar a importância crucial da } \\
\text { água e do saneamento para todas } \\
\text { as três dimensões do desenvolvi- } \\
\text { mento sustentável. } \\
\text { Reconhecemos a gravidade da per- } \\
\text { da global da diversidade biológica } \\
\text { e da degradação dos ecossistemas } \\
\text { e enfatizamos que eles minam o } \\
\text { desenvolvimento global e afetam a } \\
\text { segurança alimentar e nutricional, o } \\
\text { abastecimento e o acesso à água e } \\
\text { a saúde dos pobres rurais e pessoas } \\
\text { em todo o mundo, incluindo as } \\
\text { gerações presentes e futuras. }\end{array}$ \\
\hline
\end{tabular}

\begin{tabular}{|c|c|}
\hline $\begin{array}{c}\text { Documento } \\
\text { internacional }\end{array}$ & Fundamentação \\
\hline $\begin{array}{l}\text { Opinião Con- } \\
\text { sultiva n. } 23 \\
(2017)\end{array}$ & $\begin{array}{l}\text { Portanto, os Estados devem se } \\
\text { abster de (i) qualquer prática ou } \\
\text { atividade } \\
\text { Negar ou restringir o acesso, em } \\
\text { igualdade de condições, aos requisi- } \\
\text { tos de uma vida dignos, como são, } \\
\text { água e alimentação adequada, entre } \\
\text { outros (...) O Tribunal referiu-se } \\
\text { ao acesso e à qualidade da água, } \\
\text { alimentação e saúde, cujo conteúdo } \\
\text { já foi definido na jurisprudência } \\
\text { deste Tribunal, indicando que essas } \\
\text { condições têm um impacto agudo } \\
\text { sobre o direito a uma existência } \\
\text { digna e as condições básicas para o } \\
\text { exercício. de outros direitos huma- } \\
\text { nos (...) Por outro lado, o acesso } \\
\text { à água e aos alimentos pode ser } \\
\text { afetado, por exemplo, se a polu- } \\
\text { ição limitar sua disponibilidade em } \\
\text { quantidades suficientes ou afetar } \\
\text { sua qualidade. De referir que o } \\
\text { acesso à água inclui o acesso "para } \\
\text { uso pessoal e doméstico" que inclui } \\
\text { “consumo, saneamento, lavandaria, } \\
\text { preparação de alimentos e higiene } \\
\text { pessoal e doméstica", bem como } \\
\text { para alguns indivíduos e grupos } \\
\text { também incluirá "Recursos hídricos } \\
\text { adicionais devido à saúde, clima e } \\
\text { condições de trabalho. O acesso à } \\
\text { água, alimentação e saúde são obri- } \\
\text { gações de realização progressiva, } \\
\text { no entanto, os Estados têm obri- } \\
\text { gações imediatas (...) }\end{array}$ \\
\hline $\begin{array}{l}\text { Acordo de } \\
\text { Escazu (2018) }\end{array}$ & $\begin{array}{l}\text { Cada Parte deverá tomar medidas } \\
\text { para estabelecer um registro das } \\
\text { emissões e transferências de po- } \\
\text { luentes para o ar, água, solo e sub- } \\
\text { solo, e de materiais e resíduos sob } \\
\text { sua jurisdição, que será estabeleci- } \\
\text { do progressivamente e atualizado } \\
\text { periodicamente. }\end{array}$ \\
\hline
\end{tabular}

Fonte: elaboração própria. 
Gráfico 2 - distribuição da água doce compartilhada nos continentes

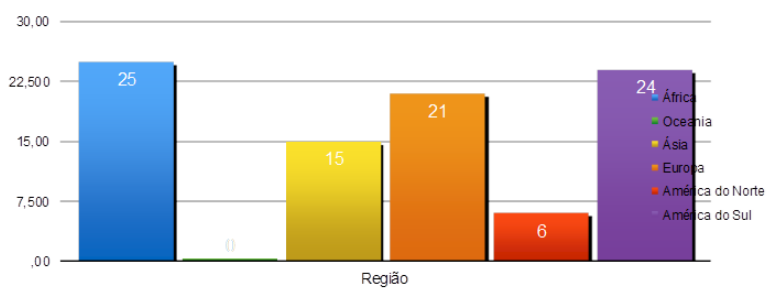

Fonte: Hernandéz Ulate $e t$ al..$^{73}$

Tem-se esse conjunto de fundamentos mais gerais destacados no quadro 3 e também normas internacionais que compõem o que se pode classificar como Direito Internacional da Água (DIA), subramo do Direito Internacional Público (DIP), que rege as relações entre Estados ou entre Estados e organizações internacionais em questões relacionadas àágua ${ }^{74}$. No quadro 4 , apresentam-se as demais normas que compõem mais especificamente o DIA, complementando o quadro 3.

Quadro 4 - conjunto de normas que compõem o DIA

\begin{tabular}{|l|l|} 
Normas & Teor \\
\hline $\begin{array}{l}\text { Resolução de Madrid } \\
\text { (1911) }\end{array}$ & $\begin{array}{l}\text { relativa à utilização de água } \\
\text { e cursos de água para usos } \\
\text { distintos da navegação. }\end{array}$ \\
\hline $\begin{array}{l}\text { Resolução de } \\
\text { Salzburgo (1961) }\end{array}$ & $\begin{array}{l}\text { abordava o direito dos Esta- } \\
\text { dos para o uso das águas e } \\
\text { dos cursos de água interna- } \\
\text { cionais para fins distintos da } \\
\text { navegação. }\end{array}$ \\
\hline $\begin{array}{l}\text { Normas de Helsinki } \\
\text { (1966) }\end{array}$ & $\begin{array}{l}\text { aborda o uso das águas dos } \\
\text { rios internacionais. }\end{array}$ \\
\hline $\begin{array}{l}\text { Conferência das } \\
\text { Nações Unidas sobre } \\
\text { a água (Mar del Plata, } \\
\text { 1977) }\end{array}$ & $\begin{array}{l}\text { tos dos Estaração abordou o direi- } \\
\text { tilham água com outros para } \\
\text { utilização equitativa como } \\
\text { forma de fortalecimentos } \\
\text { dos vínculos de solidariedade } \\
\text { e cooperação. }\end{array}$ \\
\hline $\begin{array}{l}\text { Resolução de Atenas } \\
\text { (1979) }\end{array}$ & $\begin{array}{l}\text { relativa à contaminação de } \\
\text { rios e lagos. }\end{array}$ \\
\hline
\end{tabular}

\footnotetext{
73 HERNÁNDEZ ULATE, A.; RAMÍREZ, A. L.; ELIZONDO, A. J. Gobernabilidad e instituciones en las Cuencas Transfronterizas de América Central y México. San José, C.R.: FLACSO, 2009.

74 CAPONERA, D. A. Principles of Water Law and Administration. London: Taylor and Francis Group, 2007.
}

\begin{tabular}{l|l|} 
Normas & Teor \\
\hline $\begin{array}{l}\text { Normas de Montreal } \\
(1982)\end{array}$ & $\begin{array}{l}\text { relacionadas com a contami- } \\
\text { nação das águas. }\end{array}$ \\
\hline $\begin{array}{l}\text { Normas de Seúl } \\
(1986)\end{array}$ & $\begin{array}{l}\text { referente às águas } \\
\text { subterrâneas. }\end{array}$ \\
\hline $\begin{array}{l}\text { Conferência das } \\
\text { Nações Unidades } \\
\text { sobre Água e Meio } \\
\text { Ambiente (1992) }\end{array}$ & $\begin{array}{l}\text { água e desenvolvimento } \\
\text { sustentável, estabelecendo } \\
\text { princípios basilares que fun- } \\
\text { damentam a implementação } \\
\text { de uma gestão integrada. }\end{array}$ \\
\hline $\begin{array}{l}\text { A Convenção de } \\
\text { Nova Iorque (1997) }\end{array}$ & $\begin{array}{l}\text { sobre o uso de cursos de } \\
\text { água para fins distintos da } \\
\text { navegação. }\end{array}$ \\
\hline $\begin{array}{l}\text { Resolução sobre o } \\
\text { direitos dos aquífe- } \\
\text { ros transfronteiriços } \\
\text { (2008) }\end{array}$ & \begin{tabular}{l} 
aquíferos transfronteiriços. \\
\hline
\end{tabular}
\end{tabular}

Fonte: GLOBAL WATER PARTNERSHIP ${ }^{75}$.

Portanto, tem-se um arcabouço que pode ser classificado como a fonte do Direito Internacional da Água, fundamentando, assim, a tomada de decisão nos países e nos organismos internacionais acerca dos múltiplos usos compartilhados das águas transfronteiriças, superficiais ou subterrâneas. Silva e Brant $^{76}$ mencionam esse direito como um direito internacional fluvial. Entretanto, datavenia, é mais adequado e geral na sua aplicação a classificação desse arcabouço normativo como sendo direito internacional da água. Assim, assemelha-se a algo mais geral e que destaca a relevância da água como elemento de conexão entre as nações, buscando uma convergência de interesses. Segundo Bulto ${ }^{77}$ a preocupação central desse direito deveria ser com a realização ou concretização do direito humano à água. Para isso seria imprescindível planejar ações mais holísticas de proteção da água para a sustentação da vida no planeta.

GLOBAL WATER PARTNERSHIP. El derecho internacional de agua en America Latina. Montevideo: GWP, 2015.

76 SILVA, M. E. R. A.; BRANT, L. N. C. O regime jurídico do curso de água internacional e a liberdade de navegação: o caso Costa Rica versus Nicarágua. Revista da Faculdade Mineira de Direito, v. 22, n. 44, 2019.

77 BULTO, T. S. Muito familiar para ignorar, muito novo para reconhecer: a situação do direito humano à água em nível global. In: CASTRO, J. E.; HELLER, L.; MORAIS, M. da P. O direito à água como política pública na América Latina: uma exploração teórica e empírica. Brasília: IPEA, 2015. 
Platiau e Varela ${ }^{78}$ apontam a efetividade como uma questão crucial para o direito internacional ambiental, o que afeta, também, o direito internacional da água. A efetividade é a finalidade que deve ser perseguida por toda e qualquer norma, ela deve ter eficácia real, o que passa por uma aceitação comunitária, incluindo os estados envolvidos e a sociedade que deve perceber a importância do resultado prático dessas normas internacionais em suas vidas. Cecconello ${ }^{79}$ tem razão quando argumenta que a sustentabilidade precisa ser o fio condutor desses acordos internacionais sobre o uso de águas transfronteiriças.

\subsection{A hidrodiplomacia}

Parece faltar justamente um engajamento efetivo dos Estados parte no sentido de constituir uma hidrodiplomacia forte o suficiente para tornar efetivas essas normas, inclusive sendo signatários desses acordos, tratados e convenções. Essa ação diplomática será crucial em um futuro de mudanças climáticas, na medida em que a escassez da água será uma realidade em muitas fronteiras em que isso não era comum ${ }^{80}$. As soluções resultantes de uma cooperação comunitária serão estratégicas para o desenvolvimento sustentável baseado em uma gestão integrada da água. Elias ${ }^{81}$ aponta que a gestão e governança interna de cada país importará para um resultado internacional satisfatório. $\mathrm{O}$ ponto de partida é o reconhecimento efetivo da bacia hidrográfica como unidade de gestão e governança das águas internacionais, o que desafia o modelo tradicional político-administrativo. Elias ${ }^{82}$ é bastante cirúrgico quando assevera o que a hidrodiplomacia deve almejar: "la naturaleza preventiva de la diplomacia para mantener la

78 PLATIAU, A. F. B.; VARELLA, M. D. A efetividade do direito internacional ambiental. Brasília: UniCEUB, 2007.

79 CECCONELLO, E. L. Aquífero Guarani: diagnóstico tridimensional do direito às águas subterrâneas. Novos Cadernos NAEA, v. 22, n. 1, p. 33-50, jan./abr. 2019

80 FERREIRA, C. Os Hidroconflitos e a hidrodiplomacia na gestão das bacias hidrográficas internacionais. O caso Ibérico. In: SIMPÓSIO BRASILEIRO DE GEOGRAFIA FÍSICA APLICADA, 17. 2017, Campinas. Anais [...]. Campinas, SP: Unicamp, 2017.

81 ELIAS, G. ¿Es posible una diplomacia de aguas en América Latina? Marco para una cooperación internacional en la gestión hídrica de cuencas transfronterizas. Anuario en Relaciones Internacionales, p. 1117, 2017.

82 ELIAS, G. ¿Es posible una diplomacia de aguas en América Latina? Marco para una cooperación internacional en la gestión hídrica de cuencas transfronterizas. Anuario en Relaciones Internacionales, p. 1117, 2017. p. 14. paz y la seguridad, la necesidad de diálogo en el cual se complemente la diplomacia bilateral tradicional con la diplomacia multilateral y de varios niveles, y la noción de responsabilidad colectiva de la comunidad internacional".

A hidrodiplomacia age no sentido de fortalecer o arcabouço jurídico de modo que seja cumprido e que haja um compartilhamento da água nas bacias hidrográficas internacionais baseado em parâmetros justos. É importante ressaltar que a gestão integrada de águas transfronteiriças tornou-se uma agenda estratégica para a concretização dos Objetivos do Desenvolvimento Sustentável (ODS), especificamente no item 6.5 que estabelece como meta até 2030, implementar a gestão integrada dos recursos hídricos em todos os níveis ${ }^{83}$. A compreensão absoluta de soberania não cabe mais no contexto internacional. $\mathrm{Na}$ verdade, o conceito absoluto de soberania está fragilizado, principalmente em relação às agendas tão cruciais para a manutenção da vida como a água e a proteção do meio ambiente de forma geral. Uma premissa que se pode ter nesse âmbito é que a governança de recursos hídricos, de forma compartilhada entre países, será extremamente dificultada se não houver um despojamento de conceitos arraigados na seara das relações internacionais.

A hidrodiplomacia exige competências e conhecimentos muito específicos que inclui o conhecimento das relações sociais, políticas, econômicas e ambientais entre os países em potencial conflitos em face da água. Obviamente, sua função precípua é evitar o conflito. Um dos conflitos de décadas é o que está se desenvolvendo sobre o rio Nilo, envolvendo Egito, Etiópia e Sudão, por causa da construção de uma megabarragem no segundo ${ }^{84}$. A grande questão que está em jogo é a matriz energética da Etiópia que depende da represa da Grande Renascença para poder por em curso o projeto de desenvolvimento. De outro lado, está o Egito que alega os potenciais danos a serem causados, que podem atingir mais de 100 milhões de habitantes. Atualmente, a maior pendência está na quantidade de água que a Etiópia libertará a jusante da barragem se ocorrer uma seca

83 QUADROS, J. R.; SILVA FILHO, E. C. Direito internacional de águas e soberania: velhas e novas antinomias. Pensar, Fortaleza, v. 24, n. 1, p. 1-13, jan./mar. 2019.

${ }^{84}$ ACORDO à vista entre Egito, Sudão e Etiópia sobre barragem do Nilo Azul? Agência Lusa, 2020. Disponível em: https://www. dw.com/pt-002/acordo-à-vista-entre-egito-sudão-e-etiópia-sobrebarragem-do-nilo-azul/a-53966115. Acesso em: 13 abr. 2021. 
de vários anos. E, como a Etiópia, o Egito e o Sudão resolverão divergências futuras. Isso passa, também, pela liderança regional do Egito, pois o alto volume de estoque da água necessário para o reservatório da represa é de cerca de 74 bilhões de metros cúbicos de água, o que segundo relatórios egípcios pode ameaçar os fluxos de água que chegam no Egito ${ }^{85}$, como supracitado. Além disso, os conflitos por água na região, não se remetem a esse século, porém há muito tempo que os conflitos ocorrem, e pensando no papel regional do Nilo aí pode-se falar em séculos de história ${ }^{86}$.

$\mathrm{Na}$ América Latina, tem-se um exemplo resultante da hidrodiplomacia, diferentemente da questão no Nilo, que foi o acordo do Aquífero Guaraní. O sistema Aquífero Guarani é o maior manancial de águas subterrâneas da América Latina, cobrindo cerca de 1,1 milhões de $\mathrm{km}^{2}$, sendo $71 \%$ desse total no Brasil, 19,1\% na Argentina, $6,1 \%$ no Paraguai e 3,8\% no Uruguai, atendendo cerca de 92 milhões de habitantes e 400 cidades, muitas são abastecidas totalmente pela água do aquífero, utilizada para múltiplos usos, tais como: abastecimento, indústria, agricultura e outros ${ }^{87}$. Ademais, é importante alertar que a água é um elemento potencializador de conflitos e também pode ser o caminho para o estabelecimento de acordos, especialmente quando se está em uma região cujos múltiplos usos da água podem contribuir para o esgotamento desse recurso, bem como sua contaminação. No caso dos aquíferos é sumamente importante que os países envolvidos acertem planos de preservação integrada das zonas de recarga que, via de regra, estão inseridas em regiões de grande pressão urbana e agropecuária. No caso do aquífero guarani, já é possível constatar territórios contaminados e salinizados, sendo a solução para mitigação desses efeitos o estabelecimento de uma acordo que enseje uma gestão integrada desse recurso ${ }^{88}$.

85 BRANDÃO, L.; GERBASE, L. Geopolítica dos recursos hídricos transfronteiriços: conflito e cooperação no compartilhamento da bacia do rio Nilo e do rio Zambeze. Século XXI, Porto Alegre, v. 7, n. 2, jul./dez. 2016.

86 GARCIA, T. L. S.; ZACARELLI, M. A. Geopolítica e diplomacia na Bacia Hidrográfica do Nilo. Revista de Geopolitica, Natal, v. 3, n. 2, p. 248-262, jul./dez. 2012.

87 WALSCHOT, M. Hidro-diplomacia y soberanía nacional en el acuífero guaraní: ¿fracaso de un intento de gestión transfronteriza por intereses geopolíticos divergentes? Agua y Território, n. 15, p. 21 34, 2019.

88 RFI. Especialista da FAO alerta para contaminação do Aquifero Guarani no Brasil. 2019. Disponível em: https://www.rfi.fr/br/ brasil/20190821-especialista-da-fao-alerta-para-contaminacao-do-aquifero-guarani-no-brasil. Acesso em: 14 abr. 2021.
É importante destacar, também, que a necessidade de um acordo sobre o Sistema Aquífero Guarani (SAG) tornou-se relevante pela proeminência da questão ambiental no âmbito do Mercosul. Isso resultou em 2010 na assinatura de um acordo entre os 4 países objeto dos serviços ecossistêmicos do aquífero, cujos objetivos compreendem a proclamação de soberania sobre o recurso hídrico, obrigação de cooperação no intercâmbio de informações, o estabelecimento de método de solução de controvérsias e, até mesmo, a promoção da conservação e proteção ambiental do SAG ${ }^{89}$. O desafio do SAG e de outros sistemas é a integração de planejamento e ações em torno de uma unidade político-administrativa de gestão dos recursos hídricos, a bacia hidrográfica $^{90}$. Em 2021 entrou em vigor o acordo referente ao SAG e segundo Hirata et al. ${ }^{91}$ isso representa um rol de avanços, quais sejam:

1) a entrada em vigor do Acordo Guarani atrairá mais investimentos e financiamentos aos quatro países, permitindo o retorno de projetos que trarão mais conhecimento técnico e científico do aquífero, por meio de programas ambientais e de cooperação internacional.

2) A entrada em vigor do Acordo Guarani não representa uma restrição indevida à soberania nacional de seus países, mas a promoção do intercâmbio das melhores práticas de gestão das águas subterrâneas, através da institucionalização do próprio Acordo e de reuniões regulares, quando os países apresentarão suas comunicações de forma voluntária.

3) A entrada em vigor do Acordo Guarani levará seus países à vanguarda da cooperação sobre águas internacionais, considerando-se o número ainda baixo de acordos vigentes entre países sobre aquíferos transfronteiriços.

4) A entrada em vigor do Acordo Guarani contribuirá para o cumprimento de importantes metas, indicadores e requerimentos processuais de tratados internacionais que os quatro países já assinaram, tais como as do De-

89 BUCHE, P. G.; Brzezinski, M. L. N. L. O Aquífero Guarani: uma análise sobre da imprensa sobre o acordo. Revista Orbis Latina, Foz do Iguaçu, v. 8, n. 2, p. 105-135, jul./dez. 2018.

90 ELIAS, G. Marco para una gobernanza del agua: havia una cooperación en cuencas transfronteirizas. BJIR, Marília, v. 7, n. 1, p. 83112, jan./abr. 2018. Disponível em: https://doi.org/10.36311/22377743.2018.v7n1.01.p83 Acesso em: 13 abr. 2021.

91 HIRATA, R.; SINDICO, F.; MANGANELLI, A. A importância da entrada em vigor do Acordo do Sistema Aquífero Guarani. Policy Brief, n. 6, abr. 2017. 
senvolvimento Sustentável e do Acordo de Paris sobre as Mudanças Climáticas Globais.

O pressuposto básico desse acordo, e de outros que venham ser estabelecidos no planeta, deve focar em garantir a segurança hídrica, compreendida como um conceito amplo que envolve direitos humanos básicos, qualidade da água, perspectiva de gênero, participação da sociedade civil, controle social das leis, orçamento para ciência e tecnologia, transparência de governo e empresas, recuperação ambiental e dos serviços ecossistêmicos, vontade política, prioridades claras e programas públicos e, principalmente, negociação pacífica dos múltiplos usos da água transfronteiriça através da hidrodiplomacia ${ }^{92}$. $\mathrm{Na}$ figura 8 , apresenta-se uma grande potencialidade de haver cada vez mais a necessidade de uma hidrodiplomacia para evitar conflitos pela água.

Figura 8-mapa de potenciais conflitos pela água

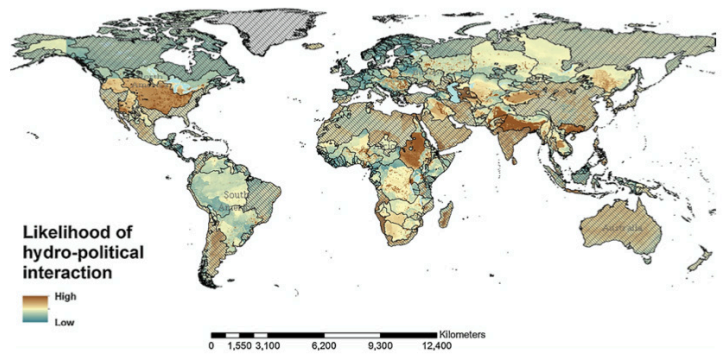

Fonte: Farinosi et al. ${ }^{93}$

\section{Considerações finais}

O quadro internacional de múltiplos usos da água apresenta uma complexidade considerável. Porém, impõe alguns elementos essenciais para desenvolver uma relação equilibrada entre os países que compartilham mananciais de uma ou várias bacias hidrográficas: governança eficiente da água no plano interno ao país; compromisso com uma agenda ambiental; compromisso com a implementação de mecanismos de gestão integrada da água e a clareza que é fundamental fiscalizar os usos e buscar um modelo racional.

\footnotetext{
92 SPRING, U. O. La seguridad del agua en México. México: Centro Tepoztlán Víctor L. Urquidi, AC, 2018.

93 FARINOSI, F. et al. An innovative approach to the assessment of hydro-political risk: A spatially explicit, data driven indicator of hydro-political issues. Global Environmental Change, n. 52, p. 286-313, 2018.
}

Para que isso ocorra, será preliminarmente essencial ter a exata noção que se está diante de uma estrutura político-administrativa diferenciada daquela que as burocracias estatais dos países estão acostumadas, pois o espaço geográfico em que se implementará ações de hidrodiplomacia será a bacia hidrográfica. Dessa forma, a participação e o diálogo devem permear as tomadas de decisão. Quando se está diante de um conflito envolvendo mananciais de água transfronteiriços e se necessita de acordos e tratados para negociar entre nações a quantidade e a qualidade desse líquido, está-se diante do exercício da hidroplomacia.

Esse escopo basilar ganha importância em um contexto de superexploração da água em escala mundial, potencializado com as dinâmicas que caracterizam as mudanças climáticas. Dessa forma, as demandas econômicas e produtivas em geral, somadas às mudanças climáticas, contribuem para o panorama de escassez da água. Esse elemento ajuda a pensar um futuro de competição entre os países por esse recurso tão decisivo para a vida, o que torna uma hidrodiplomacia essencial para proteger os interesses comunitários em regiões dos diversos continentes.

Já se tem um background normativo pujante, como demonstrado neste ensaio, apesar da resistência de vários países em ser signatários. Entretanto, é preciso avançar em instrumentos multilaterais que possam implementar ações ecológicas com a finalidade de preservação dos mananciais de água bem definidos. A execução de uma gestão integrada e compartilhada nas bacias transfronteiriças é fundamental para o cumprimento dos Objetivos de Desenvolvimento Sustentável, com destaque para o objetivo 6 , item 6.5 , além do objetivo 11, o primeiro tratando do acesso à água e ao saneamento de modo universal, e o segundo abordando as cidades resilientes como fundamentais para um mundo em metamorfose climática.

Para que o princípio participativo internacional seja viável, é essencial que os comitês de bacias transfronteiriças funcionem, cuja experiência seja exitosa em âmbito nacional e possa ser projetado para a escala internacional. Com isso, a cooperação deve existir entre os países e não uma competição por água, mediada por uma hidrodiplomacia preparada desde o planejamento dos múltiplos usos da água à jusante e à montante. Essa é uma tarefa árdua no plano jurídico e da gestão pública em cada país envolvido. Porém isso pode ser viabilizado 
por meio de um esforço governamental em aproximar seu corpo diplomático das questões hídricas que envolvem cada país, treinando e capacitando para que se conheça a fundo os múltiplos usos da água, e as questões de fundo presentes nessa dinâmica.

\section{Referências}

ACORDO à vista entre Egito, Sudão e Etiópia sobre barragem do Nilo Azul? Agência Lusa, 2020. Disponível em: https://www.dw.com/pt-002/acordo-à-vistaentre-egito-sudão-e-etiópia-sobre-barragem-do-niloazul/a-53966115. Acesso em: 13 abr. 2021.

ALBA, F. de. Geopolítica del agua en México: la oposición entre la hidropolítica y el conflicto sociopolítico. Los nuevos rostros de las "luchas" sociales. Revista Internacional de Desenvolvimento Local, v. 8, n. 1, p. 95-112, mar. 2007.

BRANDÃO, L.; GERBASE, L. Geopolítica dos recursos hídricos transfronteiriços: conflito e cooperação no compartilhamento da bacia do rio Nilo e do rio Zambeze. Século XXI, Porto Alegre, v. 7, n. 2, jul./dez. 2016.

Bruckmann, M. Recursos naturales y la geopolitica de la integración sudamericana. Instituto Perumundo; Fondo Editorial J.C.Mariátegui, 2012.

BUCHE, P. G.; Brzezinski, M. L. N. L. O Aquífero Guarani: uma análise sobre da imprensa sobre o acordo. Revista Orbis Latina, Foz do Iguaçu, v. 8, n. 2, p. 105-135, jul./dez. 2018.

BULTO, T. S. Muito familiar para ignorar, muito novo para reconhecer: a situação do direito humano à água em nível global. In: CASTRO, J. E.; HELLER, L.; MORAIS, M. da P. O direito à água como política pública na América Latina: uma exploração teórica e empírica. Brasília: IPEA, 2015.

CAPONERA, D. A. Principles of Water Law and Administration. London: Taylor and Francis Group, 2007.

CASTELLANOS, C. E. Q. Gobernanza y teoría de las organizaciones. Perfiles Latinoamericanos, v. 25, n. 50, p. 39-57, 2017.

CASTRO, Douglas de. Escassez hídrica e direito internacional econômico: o Brasil como protagonista na transferência de água para regiões áridas. Revista de Direito Internacional, Brasília, v. 13, n. 1, p. 214-227, 2016.
CECCONELLO, E. L. Aquífero Guarani: diagnóstico tridimensional do direito às águas subterrâneas. Novos Cadernos NAEA, v. 22, n. 1, p. 33-50, jan./abr. 2019.

DUNRISE, A. Manipulating Social Tensions: collibration as an alternative mode of government intervention. 1993. Disponível em: https://www.econstor.eu/bitstream/10419/43732/1/152565922.pdf Acesso em: 13 abr. 2021.

ELIAS, G. ¿Es posible una diplomacia de aguas en América Latina? Marco para una cooperación internacional en la gestión hídrica de cuencas transfronterizas. Anuario en Relaciones Internacionales, p. 11-17, 2017.

ELIAS, G. Marco para una gobernanza del agua: havia una cooperación en cuencas transfronteirizas. BJIR, Marília, v. 7, n. 1, p. 83-112, jan./abr. 2018. Disponível em: $\quad$ https://doi.org/10.36311/2237-7743.2018. v7n1.01.p83 Acesso em: 13 abr. 2021.

FARINOSI, F. et al. An innovative approach to the assessment of hydro-political risk: A spatially explicit, data driven indicator of hydro-political issues. Global Environmental Change, n. 52, p. 286-313, 2018.

FERREIRA, C. Os Hidroconflitos e a hidrodiplomacia na gestão das bacias hidrográficas internacionais. O caso Ibérico. In: SIMPÓSIO BRASILEIRO DE GEOGRAFIA FÍSICA APLICADA, 17., 2017, Campinas. Anais [...]. Campinas, SP: Unicamp, 2017.

GARCIA, T. L. S.; ZACARELLI, M. A. Geopolítica e diplomacia na Bacia Hidrográfica do Nilo. Revista de Geopolítica, Natal, v. 3, n. 2, p. 248-262, jul./dez. 2012.

GLOBAL WATER PARTNERSHIP. El derecho internacional de agua en America Latina. Montevideo: GWP, 2015.

GLOBAL WATER PARTNERSHIP. Gobernabilidad Efectiva del Agua. Montevideo: GWP, 2006.

GOMIDE, J. E.; SILVA, A. C. O surgimento da expressão "governance", governança e governarça ambiental. Revista de Ciências Gerenciais, v. 13, n. 18, 2009.

HERNÁNDEZ ULATE, A.; RAMÍREZ, A. L.; ELIZONDO, A. J. Gobernabilidad e instituciones en las Cuencas Transfronterizas de América Centraly México. San José, C.R.: FLACSO, 2009.

HIRATA, R.; SINDICO, F.; MANGANELLI, A. A importãncia da entrada em vigor do Acordo do Sistema Aquífero Guarani. Policy Brief, n. 6, abr. 2017. 
Katsamunska, P. The concept of governance and public governance theories. Economic Alternatives, n. 2, 2016.

KENNETH, P. Governance, globalization and public policy. Great Britain: Edward Elgar Publishing Limited, 2008.

KOIMMAN, J. Modern Governance: new goverment, society interactions. Great Britain: Sage, 1993.

MARK, G.; HOOGHE, L. Contrasting visions of multi-level governance. In: BACHE, I.; FLINDERS, M. Multi-level Governance. Oxford: [s.n.], 2004.

MEIER, K. J.; O’Toole L. J. Public management: organizations, governance, and performance. New York: Cambrige, 2011.

MORAES, D. S.; LICEA, D. M. El péndulo de la gobernabilidad y la governanza del agua en México. Tecnología y Ciencias del Agua, v. 4, n. 3, p. 149-163, jul./ago. 2013.

ORGANIZAÇÃO DAS NAÇÕES UNIDAS. Comercializar el agua en el mercado de futuros de Wall Street viola los derechos humanos. 2020. Disponível em: https://news. un.org/es/story/2020/12/1485432. Acesso em: 18 dez. 2020.

OSTROM, E. Beyond markets and states: polyjcentric governance of complex economic systems. American Economic Review, n. 100, p. 641-642, 2010.

OSTROM, E. Coping with tragedies of the Commons. Annu. Rev. Polit. Sci., n. 2, 1999.

OSTROM, E. Understanding Institutional Diversity. Printeton: Princeton University, 2005.

OSTROM, E.; GARDNER, R.; WALKER, J. Rules, Games and Common Pool Resources. United States of America: The University Michigan Press, 1994.

PACHECO-VEGA, R. Ostrom y la gobernanza del agua en México. Revista Mexicana de Sociología, v. 76, n. Esp., p. 137-166, set. 2014.

PATEIRO, L. M.; SINDICO, F. El valor jurídico y práctico del proyecto de artículos de la CDI sobre el derecho de los acuíferos transfronterizos. ACDI, Bogotá, v. 13, p. 19-46, 2019.

PAVÃO, B. B. M.; SALINAS, N. S. C.; VIGAR, T. do N. Regulação das águas: uma análise empírica da produção normativa dos órgãos reguladores federais. Revista Brasileira de Políticas Públicas, Brasília, v. 11, n. 1. p. 319-341, 2021.
PEREIRA, R. R. Governança no Setor Público: origem, teorias, modalidades e aplicações. Revista do TCU, n. 122, 2011.

PLATIAU, A. F. B.; VARELLA, M. D. A efetividade do direito internacional ambiental. Brasília: UniCEUB, 2007.

QUADROS, J. R.; SILVA FILHO, E. C. Direito internacional de águas e soberania: velhas e novas antinomias. Pensar, Fortaleza, v. 24, n. 1, p. 1-13, jan./mar. 2019.

RAADSCHELDERS, J. C. N.; VIGODA-GADOT, E.; KISNER, M. Global dimensions of public administration and governance. United States of America: John Wiley \& Sons, Inc., 2015.

RFI. Especialista da FAO alerta para contaminação do Aquifero Guarani no Brasil. 2019. Disponível em: https://www. rfi.fr/br/brasil/20190821-especialista-da-fao-alerta-para-contaminacao-do-aquifero-guarani-no-brasil. Acesso em: 14 abr. 2021.

RODELL, M. et al. Emerging trends in global freshwater availability. Nature, v. 557, p. 651-659, 2018.

RUSSEL, M. B.; SCOTT, C. Putting Investors First: real solutions for better corporate governance. New York: Bloomberg Press, 2003.

SAGUIER, M. et al. Interdisciplinary research networks and science-policy-society interactions in the Uruguay River Basin. Environmental Development, n. 38, 2021. Disponível em: https://www.sciencedirect.com/science/ article/pii/S2211464520301330?via\%3Dihub Acesso em: 14 abr. 2021.

SÁNCHEZ, J. C. et al. El derecho internacional de aguas en América Latina: manual de capacitación. Montevideo: GWP Sudamérica, 2015.

SILVA, J. I. A. O. Public access to information for sustainable development. In: LEAL FILHO, W. et al. (ed.) Peace, Justice and Strong Institutions: encyclopedia of the UN Sustainable Development Goals. New York: Springer, 2021.

SILVA, J. I. A. O. Segurança hídrica ecológica: fundamentos para um conceito jurídico. 2020. Tese (Doutorado em Ciências Jurídicas) - Universidade Federal da Paraíba, João Pessoa, 2020.

SILVA, M. E. R. A.; BRANT, L. N. C. O regime jurídico do curso de água internacional e a liberdade de navegação: o caso Costa Rica versus Nicarágua. Revista da Faculdade Mineira de Direito, v. 22, n. 44, 2019. 
SPRING, U. O. La seguridad del agua en México. México: Centro Tepoztlán Víctor L. Urquidi, AC, 2018.

Srinivasan, V. et al. The nature and causes of the global water crisis: Syndromes from a meta-analysis of coupled human-water studies. Water Resources Research, v. 48, 2012.

THE EARTH CHARTER INTERNATIONAL. La Carta de la Tierra +15 celebraciones y otros eventos en México. 2015. Disponível em: http://cartadelatierra.org/descubra/la-carta-de-la-tierra/ Acesso em: 13 abr. 2021.

THE WORLD BANK. Recently approved projects. Disponível em: http://projects.worldbank.org/search?la ng=en\&searchTerm $=\&$ sectorcode_exact $=$ WC Acesso em: 13 abr. 2021.

TOVAR, L. A. R.; FLORES, M. T. e VILCHIS, F. L. La gobernanza. Conceptos, tipos, e indicadores internacionales: Los retos para México. México: Alta Impresión S.A, 2015.

TRANSBOUNDARY FRESHWATER DISPUTE DATABASE. International Freshwater Treaties (by River Basin). Disponível em: http://gis.nacse.org/tfdd/treaties. php Acesso em: 13 abr. 2021.

UNESCO. Atlas of transboundary aquifers: global maps, regional cooperation and local inventories. Paris: UNESCO, 2009.

UNESCO. River and Groundwater Basins of the world. 2012. Disponível em: https://groundwaterportal.net/ resource/whymap-river-and-groundwater-basins-world Acesso em: 15 abr. 2021.

UNESCO. World Water Development Report. México: Unesco, 2019.

UNESCO. World Water Development Report. Oxford: Unesco, 2006.

UNITED NATIONS DEVELOPMENT PROGRAMME. Governance for sustainable human development. a UNDP policy document. New York: UNDP 1997.

VINUALES, J. E. The protocol on water and health as a strategy for global water governance integration. ICLQ, v. 68, p 175-192, jan. 2019.

VINUALES, J. E.; LEES, E. Comparative environmental law. United Kingdom: Oxford University Press, 2019.

WALSCHOT, M. Hidro-diplomacia y soberanía nacional en el acuífero guaraní: ¿fracaso de un intento de gestión transfronteriza por intereses geopolíticos divergentes? Agua y Território, n. 15, p. 21-34, 2019.

WOLF, A. T. et al. Water governance benchmarking: concepts and approach framework as applied to Middle East and North Africa countries. Water Policy n. 16, p. 1121-1139, 2014.

WORLD DATA ATLAS. Total Renewable Water Resources. 2017. Disponível em: https://knoema.com/atlas/topics/Water/Total-Renewable-Water-Resources/Renewable-water-resources. Acesso em: 16 abr. 2021.

WORLD RESOURCES INSTITUTE. World's 36 Most Water-Stressed Countries. 2013. Disponível em: https:// www.wri.org/insights/worlds-36-most-water-stressedcountries. Acesso em: 12 dez. 2020. 
Para publicar na Revista de Direito Internacional, acesse o endereço eletrônico www.rdi.uniceub.br ou www.brazilianjournal.org.

Observe as normas de publicação, para facilitar e agilizar o trabalho de edição. 